DOI: $10.6060 / \mathrm{mhc} 141140 \mathrm{~s}$

\title{
Glycodendrimers and Their Derivatives as Potential Therapeutic Agents
}

\author{
I. S. Shchelik, @ A. I. Magasumova, and Yu. L. Sebyakin \\ Dedicated to Professor Andrej Fedorovich Mironov on the Occasion of his 80th Birthday
}

M.V. Lomonosov Moscow State University of Fine Chemical Technology, 119571 Moscow, Russia

${ }^{\circledR}$ Corresponding authorE-mail: c-221@yandex.ru

\begin{abstract}
The carbohydrates are involved in many important biological processes such as cell recognition and cell adhesion. They are presented as a cell surface glycoconjugates, creating a characteristic layer, which surrounds the eukaryotic cell and are called glycocalyx. There is a basic molecular complex of glycocalyx which presents the class of specialized proteins called lectins. To investigate the carbohydrate-protein interactions, synthetic glycosides and glycomimetics as modulators and inhibitors of molecular recognition processes have been used. The present report deals with carbohydrate derivatives, glycolipids and neoglycoconjugates with potential antiadhesion, antiviral, antibacterial, and antitumor activities.
\end{abstract}

Keywords: Glycoconjugates, glycodendrimers, glycotherapy, anti-adhesion, carbohydrates.

\section{Гликодендримеры и дендримероподобные соединения в качестве потенциальных терапевтических агентов}

\author{
И. С. Щелик, А. И. Магасумова, Ю. А. Себякин ${ }^{\circledR}$ \\ Посвящается профессору Андрею Фёgоровичу Миронову по случаю его 80-летнего юбилея \\ Московский государственный университет тонких химических технологий им. М.В. Ломоносова, 119571 Москва, \\ Россия \\ @E-mail: c-221@yandex.ru
}

\begin{abstract}
В обзоре рассмотрены производные углеводов, гликолипидов и неогликоконъюгатов с потенциильными анти-
\end{abstract} адгезионными, антивирусныли, антибактериальными и противоопухолевыми активностями.

Ключевые слова: Гликоконъюгаты, гликодендримеры, гликотерапия, анти-адгезионные свойства, углеводы.

\section{Introduction}

At the beginning of the 20th century the advent of glycan-based therapy has marked the dawn of modern medicine. However, this therapy quickly receded into the background, as soon as DNA- and proteins-based methods of treatment have become easily available. The recent development of new tools and techniques for the study and production of carbohydrate derivatives with a certain structure revived the interest in their therapeutic use. During the last decade, the treatments based on these compounds have become relevant in medicine again. They include the use of glycans themselves as therapeutic molecules, also the producing of proteins derivatives and cell surface polysaccharides for use in clinical practice, what opens new prosperous and promising directions for studies in biopharmaceuticals and medical applications. ${ }^{[1]}$

Glycans are universal and vital components of living systems. They may be presented as big structural polysaccharides or conjugates of proteins and lipids. Sizes of 


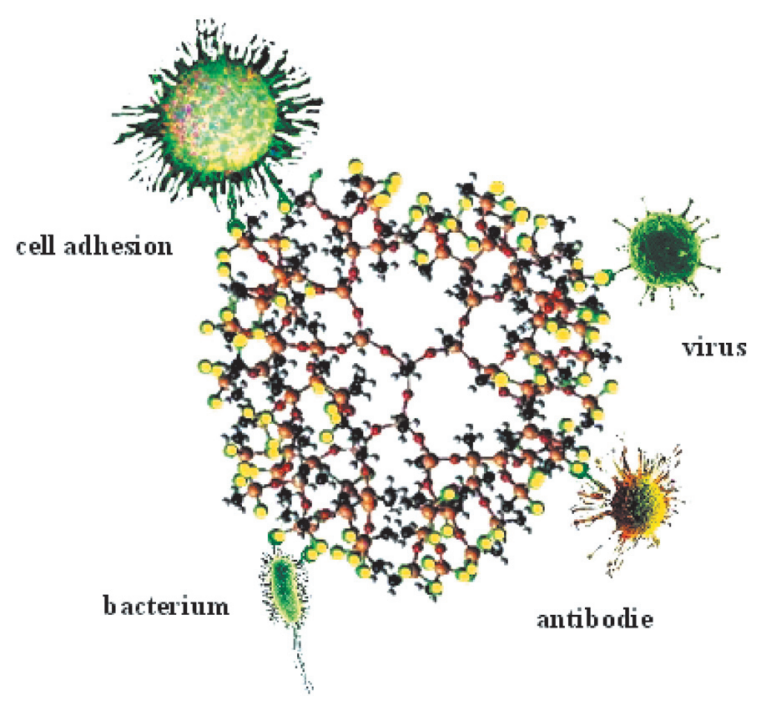

Figure 1. The examples of using the dendrimers in glycotherapy.

carbohydrates are ranged from one monosaccharide unit to thousand units in length. ${ }^{[2]}$ Carbohydrates are located on the cell surface of each of the body and are the most common class of organic molecules in the world. However, it took almost a century before scientists have evaluated the role of these molecules in biology. This gap in understanding the structure and function of the glycan has happened due to the difficult synthesis of these biomolecules. Synthesis of glycans is not directly encoded by the genome so, consequently, their biosynthesis and composition are determined by metabolism, signal transfer and cell state. Furthermore, there is a large structural diversity of carbohydrate sequences due to their possibility to be connected by various linker sand then this diversity can be increased by modifying functional groups. ${ }^{[3]}$
Nowadays it is a well-known fact that glycans play an essential role in many biological processes, such as cell adhesion and migration, development of an organism, disease progression and modulation of immune responses. [4] After decades of studying carbohydrates and working on improved methods for their synthesis, scientists started generating revised or novel saccharide derivatives in order to control human's diseases and health.

\section{Glycoconjugates in Anti-Adhesion Therapy}

The adhesion of pathogenic organisms in the host tissue is prerequisite for the initiation of various infectious diseases. In many systems it is mediated by lectins, exposed on the surface of infectious microorganisms, which are binding to the host tissue surface via complementary carbohydrates.

Mutants deprived of lectins often don't have the ability to initiate infection. Lectins on the surface of bacterium are generally presented in the form of long, thin threadlike adnexal structures that consist of protein subunits known as Fimbria.

The purpose of anti-adhesion therapy is blocking or inhibiting these lectins with suitable carbohydrates or their analogs in order to prevent and treat infectious diseases. ${ }^{[5]}$

The Type I is the most well-characterized type of pili that is capable of binding to $\alpha$-D-mannose unit in a structure of glycolipids on the surface of eukaryotic cells of different types. The attachment to a glycolipid receptor is provided by specific lectins on their ends, called FimH. Type I pili are critical virulence factors of uropathogenic $E$. coli and there are widespread among enteric bacterium. Many different mannosides and $\alpha$-D-mannose conjugates were prepared and tested as inhibitors of bacterial adhesion mediated by type I pili, predominantly in vitro (Figure 2). ${ }^{6]}$

Previously synthetic mannosides were investigated and studied, as inhibitors of bacterial adhesion to polysaccharides

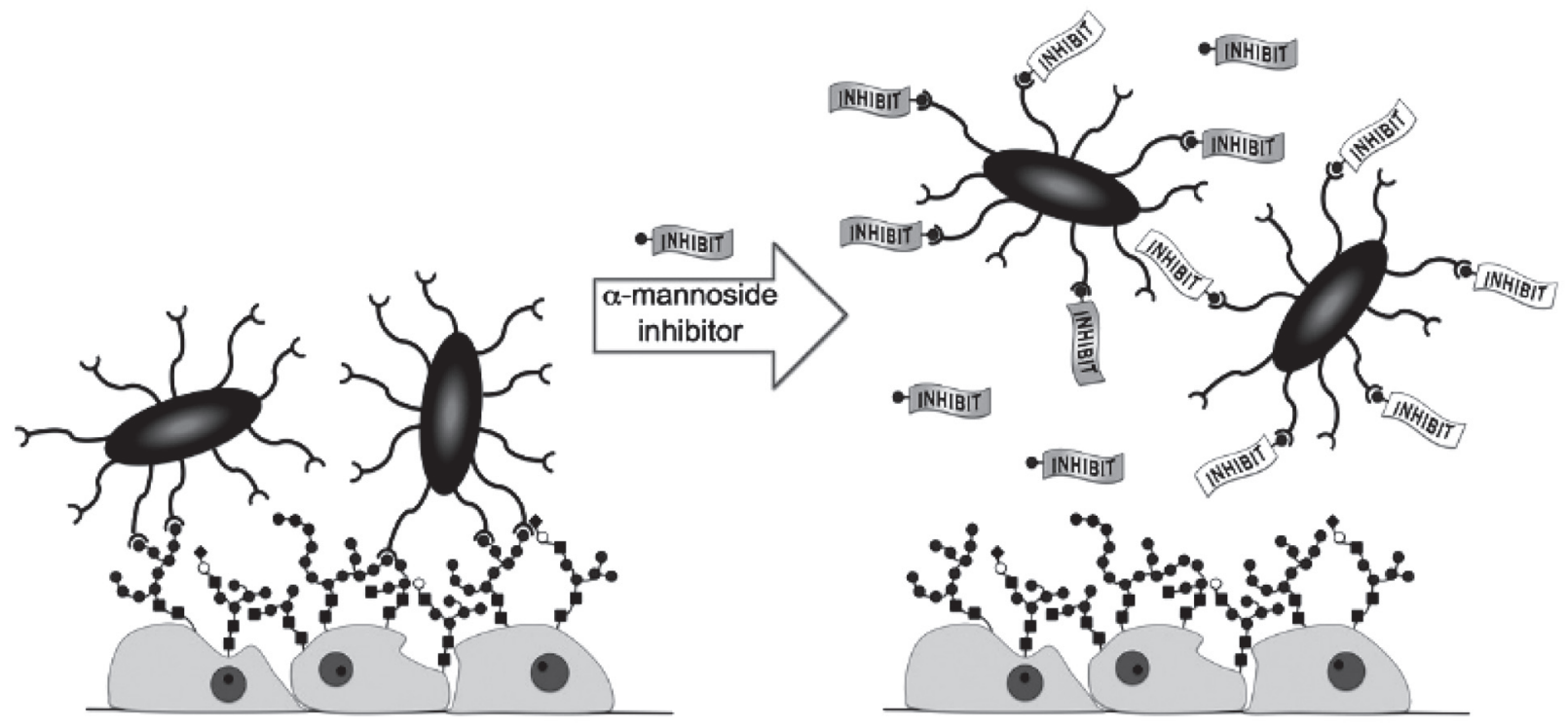

Figure 2. Picture of bacterial adhesion mediated by pili on the cell glycocalyx and its prevention by suitable $\alpha$-mannosides. ${ }^{[6]}$ 
of mannan. ${ }^{[6,7]}$ Due to the known structure of fimbrial lectin I of FimH type can significantly improve the affinity of $\alpha$-Dmannoside ligands by modifying the aglycone, while the mannose glycan moiety shouldn't be changed.

Aromatic $\alpha$-mannosides are potent inhibitors of type I pili of E. coli. Multivalent saccharides (e.g., neoglycoconjugates or dendrimers) are also potent inhibitors of bacterial adhesion in vitro. The fact that carbohydrates are not toxic or immunogenic makes them perfect agents for this purpose; in particular ones that inhibit bacterial adhesion mostly are normal cell surface components or biological fluids, such as human milk. Another point is that anti-adhesive agents do not affect the elimination or arresting the growth of pathogens, it is likely that strains resistant to such agents would occur less often than strains that are resistant to antibiotics.
Fullerenes containing 12 peripheral mannose residues by binding of carbohydrate derivatives to the fullerene core were obtained; they were studied as inhibitors of FimH. ${ }^{[8]}$ Using isothermal titration calorimetry, surface plasmic resonance and hemagglutination analysis dissociation constant in the range from 12 to $95 \mathrm{nM}$ for these compounds were determined. The number of possible interactions between the multimers and lectin and the average force of binding to a functional part of mannose were also measured by scientists. It was found out that the globular structure of C60 molecules is able to accommodate seven FimH molecules.

E. coli causes a bladder infection by expressing P-pili resulting in acute pyelonephritis. P-pili run out PapG associated by adhesin that recognizes the residue of Gal$\alpha$-(1,4)-Gal (galabiose) globular portion of the glycolipid.

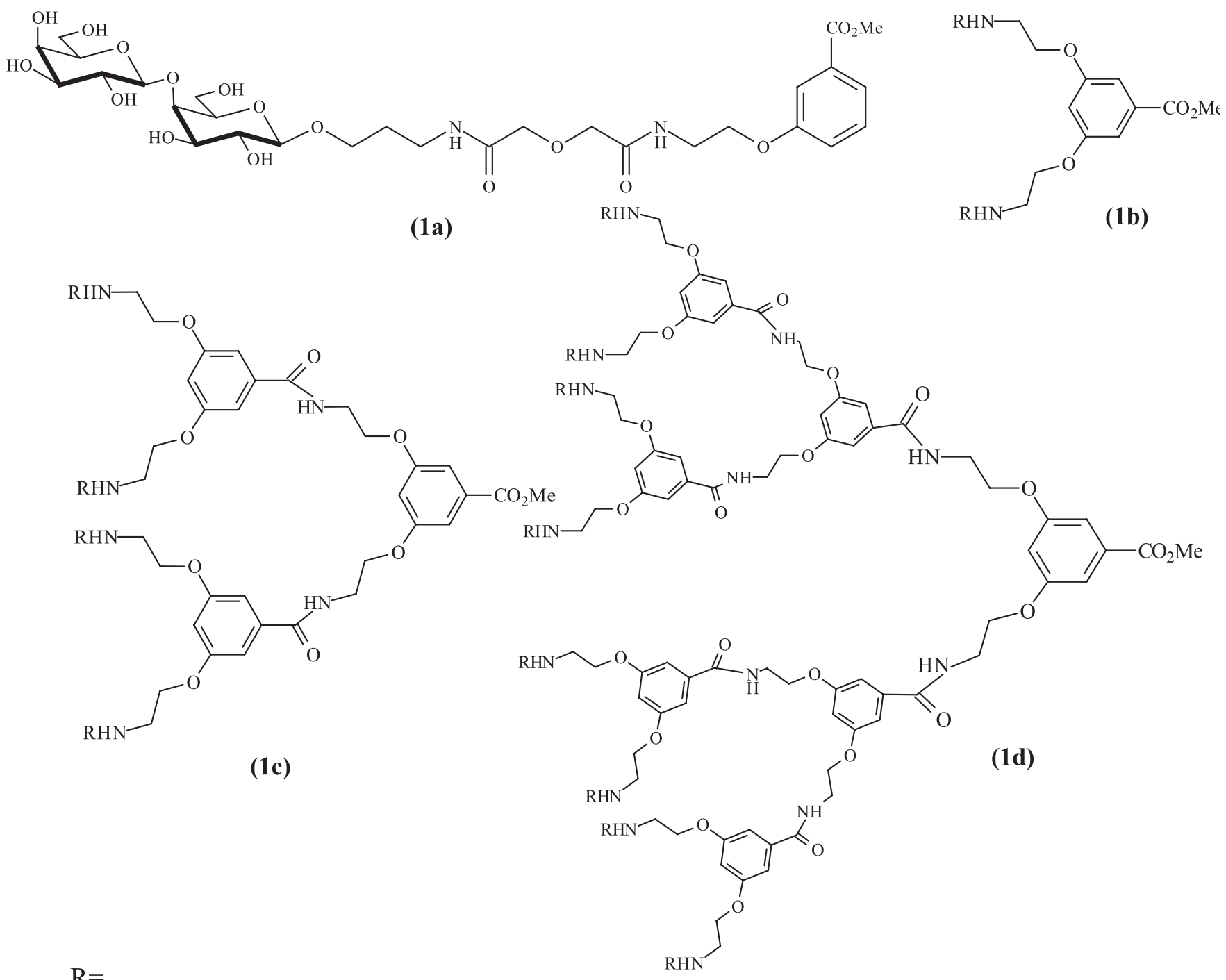

$\mathrm{R}=$

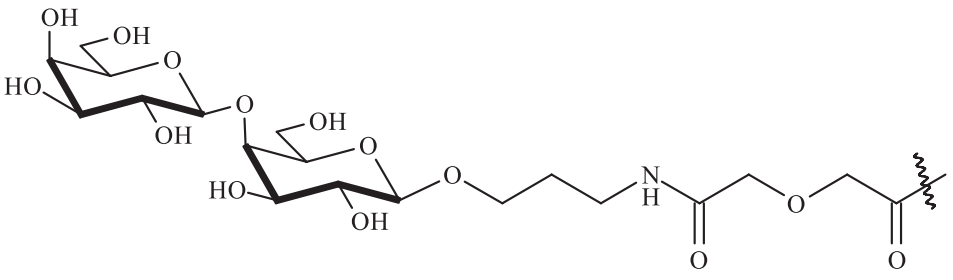


To study the adhesion inhibition with monovalent galabiose derivatives SPR analysis of live bacteria with creating natural conditions was used.

In depend on the quantity the surface of chip is coated with synthetic mono- and multivalent galabiose derivatives (1a-d), inhibiting bacterial adhesion. Octavalent galabiose compound (1d) was stronger than tetravalent (1c), divalent (1b) and monovalent (1a) derivatives. However, in the case of Streptococcus suis adhesion multivalency effect was more notice able comparing to E. coli PapG.

Pseudomonas aeruginosa is a pathogen that causes chronic respiratory infections, especially in cystic fibrosis patients. This strain synthesizes two lectins: LecA and LecB, which are playing an important role in human infections. It has been shown that solutions of galactose and fucose which are capable of bounding to LecA and LecB, respectively, have a therapeutic potential against $P$. aeruginosa pneumonia in a mouse model and in patients with cystic fibrosis. ${ }^{[9]}$ Recently it has been investigated that peptide glycomimetics have high binding affinity to both LecA and LecB, and prevent their toxic activity. ${ }^{[10]}$

LecA (also called PA-IL) is a tetrameric cytotoxic lectin consisting of four subunits of 121 amino acids (12.75 kDa) each with specificity to $\alpha$-D-galactose and, preferentially, to binding to Gal- $\alpha-(1,4)-G a l$, containing globotriacylceramide Gb3 sphingolipid. Crystal structure of LecA has an affinity to the monosaccharide $\alpha$-D-galactose with calcium ion in the binding site. In addition to its cytotoxicity, it has been suggested that this lectin contributes to the formation of bacterial microcolonies and biofilm formation.

In order to inhibit the binding of LecA with galactosylated surface many multivalent glycoconjugates were synthesized. Highly-valence compounds such as galactosylated stranded poly(phenylacetylene) polymer (2), fullerenes, or glycodendrimers (3) are effective ligands for inhibition, but their strong aggregation and precipitation properties make it difficult to measure the affinity constants. Good results have been obtained with calixarenes, $\beta$-peptoid (4), porphyrins and resorcinarenes. ${ }^{[1]}$ Among these molecules, 1,3-alternate conformer calixarene showed the greatest efficiency and increase in affinity. Chelate binding mode with two $\alpha$-D-galactose residues that interact with two adjacent binding sites in a single tetramer LecA, can be confirmed by the observation of well-defined nanoscale fibers complex lectin-glycoclaster by studying the atomic force microscopy (AFM) ${ }^{[12]}$

Recent studies have shown that it was sufficient to use divalent ligand (5) with an appropriate linker to cause the chelate effect with LecA. ${ }^{[13]}$ Hard spacer was developed based on the alternation of $\alpha$-D-glucose residues linked in the $\mathrm{C}-1$ and $\mathrm{C}-4$ positions by means of the 1,2,3-triazole part using the approach called «click chemistry». The resulting spacer was relatively hard and binded the $\alpha$-Dgalactose residues on both ends. The number of connecting units varied, as well as a spacer between the linker and the ligand $\alpha$-D-galactose. As it was shown, the linker is a very important and only compound (5) has an appropriate length in order to achieve an increase of the inhibitory potential in 545 times comparing to other compounds.

The glycopeptides dendrimers GalAG2 (6) and GalBG2 (7) was synthesized as potent ligand for lectin LecA and as dendrimeric inhibitor of biofilm $P$. aeruginosa. The multivalency of obtained compounds detects the binding with monovalent and divalent analogs, showing much weaker interactions with the lectin. ${ }^{[14]}$

LecB (also called PA-IIL) is a tetramer consisting of four $11.73 \mathrm{kDa}$ subunits with high specificity for $L$-fucose and a weaker for $D$-mannose. The LecB crystal structure revealed the occurrence of calcium ions in the binding site. This unique mode of binding is not observed in other lectins, but explains the very high affinity for fucosides and Lewis. Although LecB is cytoplasmic, it could also be detected in the outer membrane, including on the surface of biofilm cells. It is suggested, that LecB undergoes transient $N$-glycosylation that plays a role in the secretion mechanism. ${ }^{[15]}$ The search for a putative binding partner led to the proporsal of another membrane protein $\mathrm{OprF}$, that is non-specific, weakly cationselective porin protein. LecB may mediate the adhesion of $P$. aeruginosa cells to receptors, which are located on its surface and facilitate biofilm formation, promoting colonization of host tissues.

The search of high affinity ligands for LecB initiated the synthesis of several fucose-containing compounds, based on calixarene (8), pentaerythritol (9) or peptide dendrimers (10). Compounds for bivalent presentation Fuc(1-4)-GlcNAc (11) and $N$-fucosamide (12) have been also designed. ${ }^{[16]}$

The search of structure-activity relationships showed, that multivalency was important for activity, in particular divalent and linear peptide analogs of the dendrimers showed strongly reduced binding at the level of monosaccharides. These investigations led to identification of dendrimer $2 \mathrm{G} 3$ (10) with 8 terminal fucose residues as potential glycopeptide dendrimer ligand to LecB. The diastereoisomer D-36, prepared from $D$-amino acids was demonstrated to be a similarly potent ligand to LecB. ${ }^{[17]}$

Burkholderia cenocepacia is bacterium causing chronic disease such as granulomatous and cystic fibrosis with significant morbidity and mortality. A family of four soluble lectins has been identified in $B$. cenocepacia, each containing at least one domen with strong similarity of sequence with LecВ из $P$. aeruginosa ${ }^{[18]} \mathrm{BC} 2 \mathrm{~L}-\mathrm{A}$ is a small lectin consisting of the one dimer of LecB-like domen, which binds $\alpha$-D-mannose and oligomannose type of $N$-glycans.

BC2L-A has a strong affinity for $\alpha-D$-mannosides (Kd of $2 \mu \mathrm{M}$ for methyl $\alpha$-D-mannopyranoside) and mannobioses. The negotiation of interactions with the branched trimannoside Man- $\alpha$-(1,3)-Man- $\alpha-(1,6)-$ Man provide formation of molecular strings, as detected by protein crystallography. Oligomannose analogs presenting two mannosides separated by rigid (13) and flexible (14) spacer arms were researched. The rigid linker yield high affinity with a fast kinetics of clustering, while the flexible analog and the trimannoside displayed moderate affinity and no clustering. ${ }^{[19]}$

The micelles, formed from mannosylated poly(ethyleneoxide)- $b$-poly( $\varepsilon$-caprolactone) $\quad$ (PEO- $b$-PCL) diblock copolymer and nanoparticles of poly $(D-L$-lactic acid), functionalized with the same copolymer have also been demonstrated to bind efficiently to BC2L-A. ${ }^{[20]}$

In the cell wall of Gram-negative bacterium, carbohydrates are conjugated to lipids of other membrane, 
I. S. Shchelik et al.
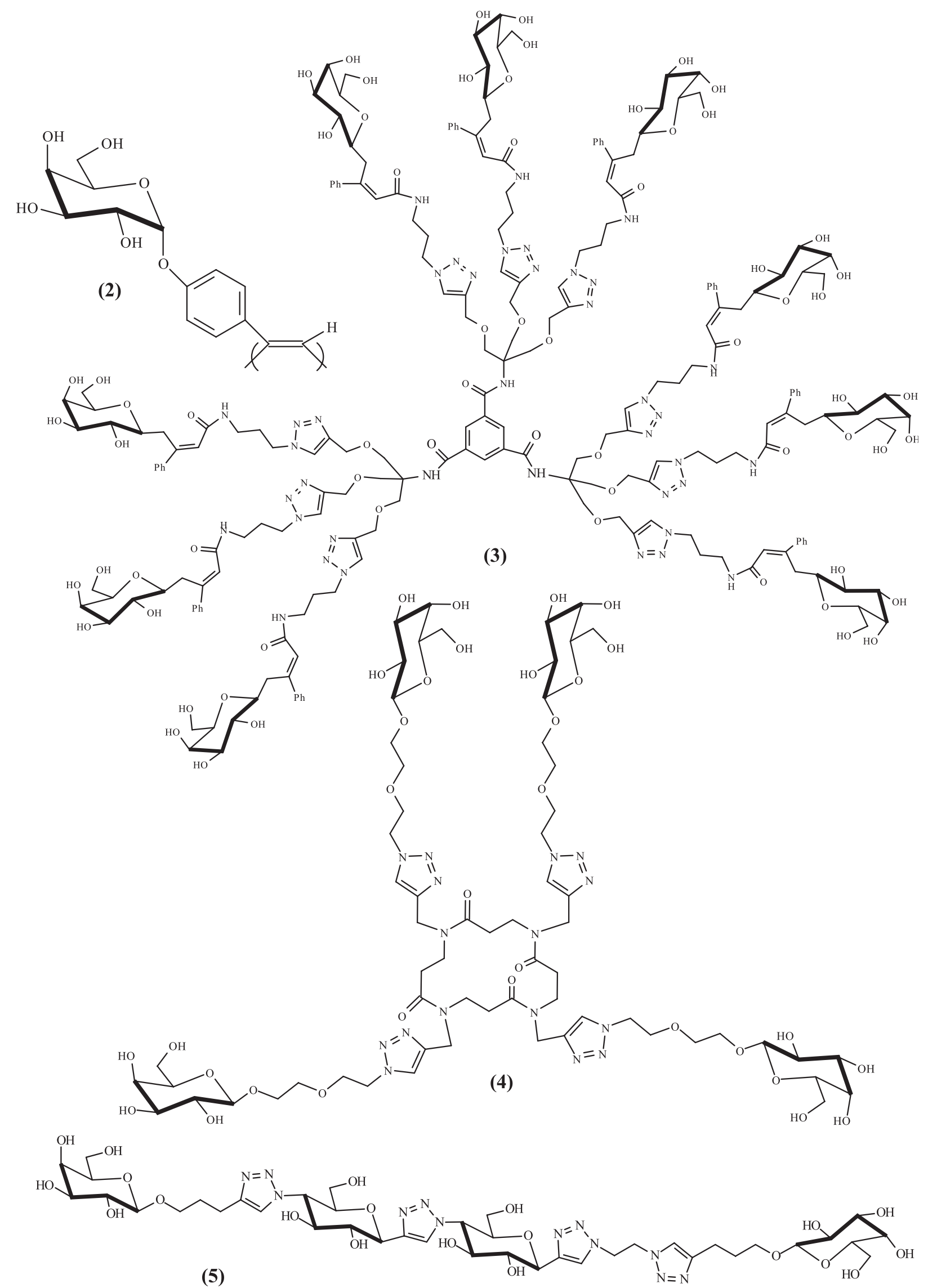


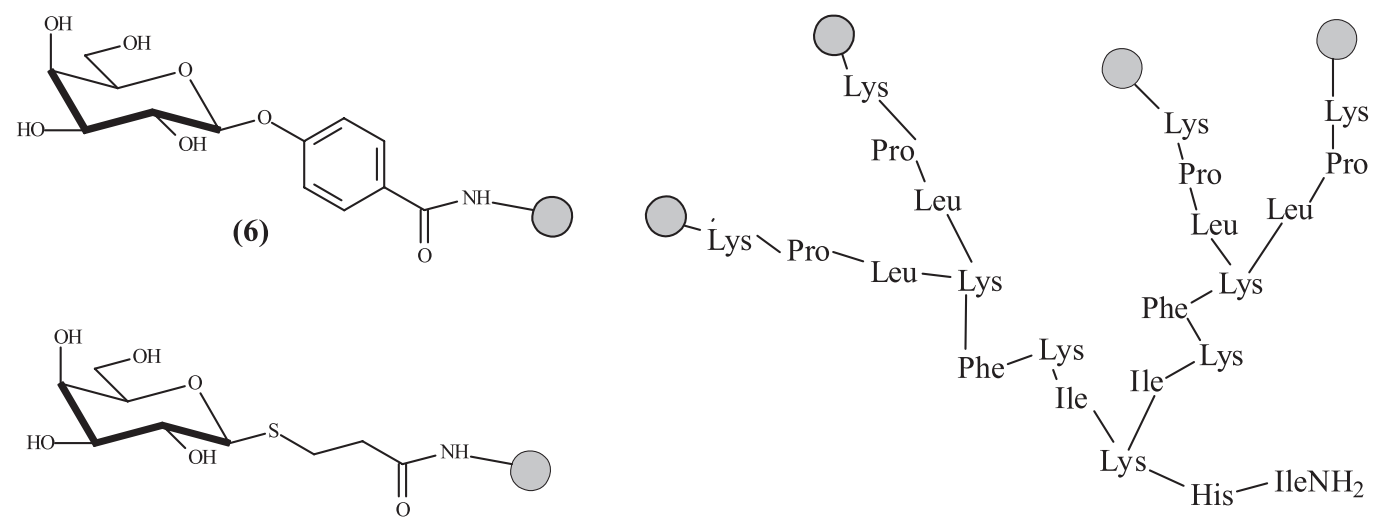

(7)

where they are present in a strong concentration. The bacterial outer membrane is asymmetric. Its enveloping layer almost completely consists of lipopolysaccharides (LPS), which generate with a multivalent glycoconjugates surface with very low fluidity and a highly ordered structure. LPSs are necessary for bacterium, this natural multivalent assembly plays important role in host-bacterium interactions.

L-Heptosides (L-glycero-D-manno-heptopyranoses) are components of the core of LPS. Since LPS are essential for bacterial viability, its biosynthesis can be target for the development of novel antibacterial agents. The fullerene derivatives, bearing twelve copies of peripheral sugars with mannopyranose core have been synthesized (15), (16). The multimers have been prepared by using an efficient $\mathrm{CuAAC}$ reaction as the final step.

The final fullerene sugar ball was assayed as inhibitor of heptosyltransferase Waac, as then the glycosyltransferase catalyzing the incorporation of the first L-heptose into LPS. The inhibition data based on the number of carbohydrates radiuses showed that, in each case, the average affinity of a single glycoside of the fullerenes towards WaaC was significantly enhanced when it displayed as a multimer, thus demonstrating an multivalent effect. ${ }^{[21]}$

Multivalent glycoconjugates are also used in anti adhesion leukacytotes to the endothelium for the prevention of inflammation.

Inflammation is an immune response to tissue injury and invasion of pathogens, in which recruitment of leukocytes from the blood to the tissue is the key process. However, excessive influx of leukocytes, under certain pathological conditions, may result in adverse reactions. For example, localization of leukocytes to the site of tissue injury can cause further tissue damages, leading to the deepening, broadening and worsening of tissue injury and also irreversible tissue necrosis and complete loss of functions. Some related disorders include ischemia and reperfusion injury, shock, systemic septicemia, severe trauma and burns, acute lung injury, and several autoimmune disorders. In all case, leukocytes are recruited to the inflamed tissue by the sequentially adhesive interactions between leukocytes and the endothelium, mediated by cell-adhesion molecules (CAMs) on the surface of the interacting cells and different kinds of CAMs are responsible for the different steps in extravasations. $^{[22]}$
The selection family of CAMs served to slow down the motion leukocytes in the blood flow direction and to promote the rolling of leukocytes along the vessel wall. The initial contact is followed by the firm adhesion leukocytes to the endothelial cells, which are mediated by the interaction of b1 and b2 integrins ( $\alpha \mathrm{L} \beta 2, \mathrm{CD} 11 \mathrm{a} / \mathrm{CD} 18$, или $\alpha \mathrm{M} \beta 2$, $\mathrm{CD} 11 \mathrm{~b} / \mathrm{CD} 18)$ on leukocytes with their corresponding receptors on endothelial cells. Strong adhesion is followed by the penetration of the leukocytes from the blood flow to the tissue. Because of the important rolls of CAMs in the multistep leukocyte batch cascade, they have been used as drug targets and their effective inhibitors are actively researched.

$\mathrm{CD} 11 \mathrm{~b} / \mathrm{CD} 18$ is a leukocyte integrin that is involved in various biological processes. It plays an important role in the firm attachment of leukocytes to endothelium. It has been reported that CD11b forms complexes with glycosylphosphatidylinositol-linkedmembraneglycoprotein, such as FccRIIIB(CD16), the urokinase plasminogen activator receptor (UPAR or CD87), or the LPS receptor CD14, thereby providing these surface bound molecules with transmembrane signaling capability.

It has been found that CD11b interacts specifically with certain sugars, including some polysaccharides containing $D$-glucose, $N$-acetyl- $D$-glucosamine and $D$-mannose. Inhibiting the activity of CD11b/CD18 by small oligosaccharides gives the possibility to design new drugs to treat several pathological diseases such as inflammations, caused by bacterial infection. ${ }^{[23]}$

In research on the treatment of severe burn shock, a clinical syndrome associated with reduced blood flow to the vital organs and tissues, it has been demonstrated, that multivalent lactosides (17-19) can effectively inhibit adhesion of leukocytes to endothelial cells. In addition, investigations on the anti-adhesion biological mechanism using labeled compounds $(\mathbf{2 0}, \mathbf{2 1})$ have revealed that the multivalent lactosides are targets of $\mathrm{CD} 11 \mathrm{~b}$ on the surface of leukocytes. However, the contribution of anti-adhesive activity of structural components of the synthetic multivalent oligosaccharides, including the class, the valence of sugar and scaffolds has not been sufficient investigated.

It has been synthesized a series of glycoclusters consisting of $D$-galactose, $D$-glucose and cellobiose and a series of multivalent lactosides with a variety of structures. 
I. S. Shchelik et al.
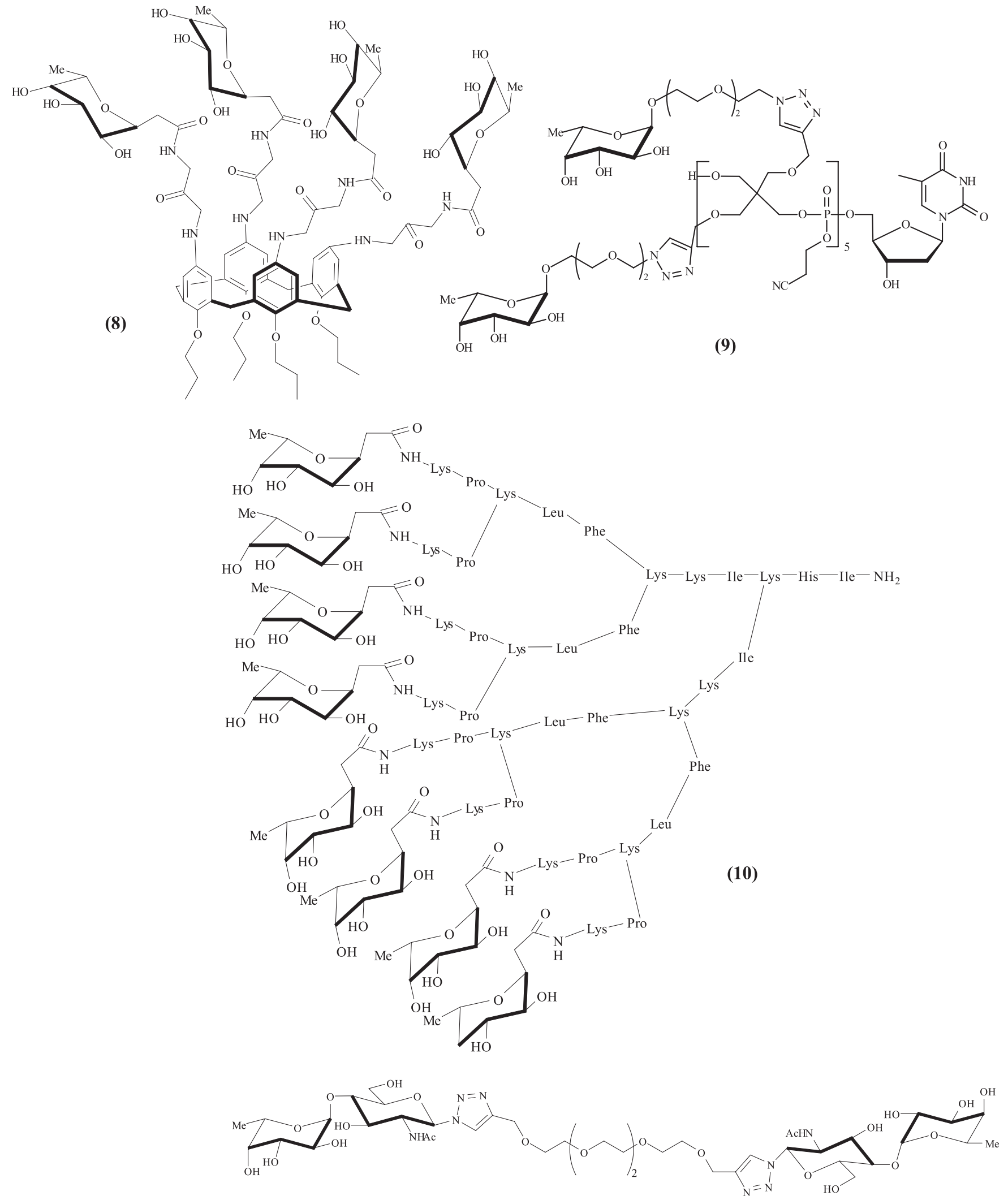

(11)

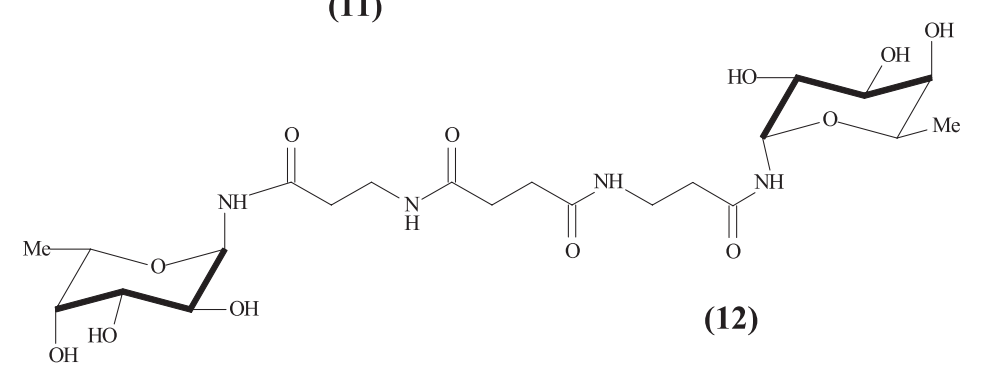




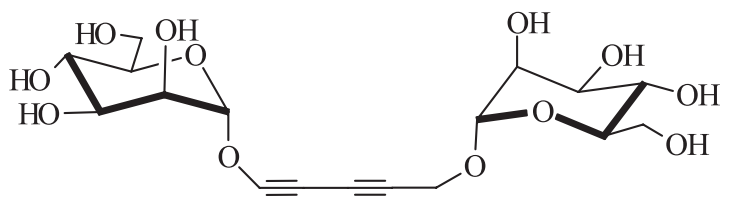

(13)

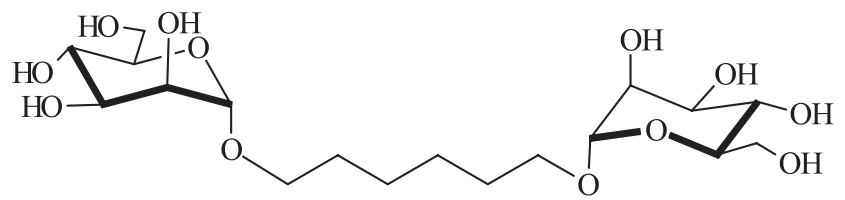

(14)

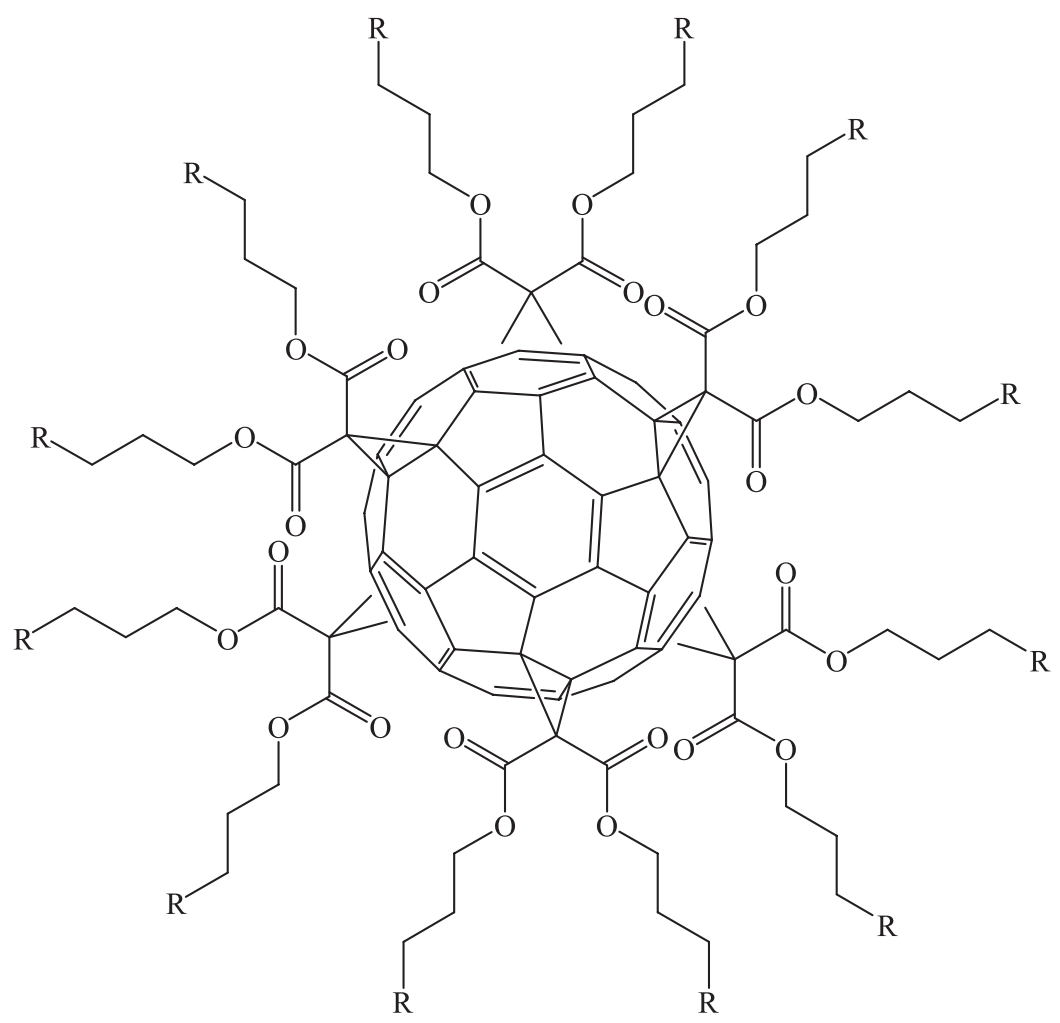

$\mathrm{R}$ :<smiles>CCOC1OC(O)[C@@H](C(O)O)C(O)C1[C@H](O)CO</smiles><smiles>C[C@@H](O)[C@@H](O)C(=O)O</smiles>

In addition, mixed-type $\alpha$-Man- $\beta$-Lac heteroglycoclusters have also been synthesized. The anti-adhesive activity of these synthesized compounds was assessed (22-26).

The results showed that anti-adhesive activity of tetravalent lactosides might be influence by the flexible linker, and the optimal flexible linker, as part of study, was L-glutamic acid. The cluster effect observations of homoglycosides suggested, that the optimal valence of multivalent glycosides was four and the optimal flexible linker was L-glutamic acid. In addition, these results suggest that anti-adhesive activities of compounds with flexible linkers are stronger than those with rigid linkers such as benzene ring.

The investigation of influence of the different sugar residues testify that tetravalent glucosides consisting of the units of D-mannose or D-glucose have sufficient antiadhesive activity. ${ }^{[24]}$

After analyzing the data obtained, symmetric octavalent glycoconjugates (27-28) with lactose and D-mannose residues were synthesized in our laboratory to investigate anti-adhesive activity to the leukocytes.

The effectivity of neoglycoconjugates binding with increase the number of lactose residues has been also studied in our laboratory. For this purpose, the interaction of earlier synthesized di-, tetra- and heptavalent glycolipids in liposomes and galactose-binding lectin of Ricinus communis $\left(R C A_{1}\right)$ has been investigated using spectrophotometric method of analysis. ${ }^{[25]}$ It is logical to assume that the glycosylated liposomes precipitating in the presence of $R C A_{1}$, will be also characterized by an increased affinity for other galactose-specificity lectins.

As a part of the study, the heptavalent compound 29 has shown the most efficient binding. This proves that the affinity of modifed liposome to lectin $R C A_{1}$ is growing with increasing the number of galactose residues. The addition of D-galactose led to reduce of optical density that indicates the specific interaction of conjugates with lectin $R C A_{1}$ (Figure 3).

\section{Multivalent Glycoconjugates against Virus Infection}

The influenza $A$ virus, which causes epidemic and pandemics in human populations is difficult to eradicate. Influenza A virus is a enveloped RNA virus, belonging to the Orthomyxo virus family and their size and shape can 


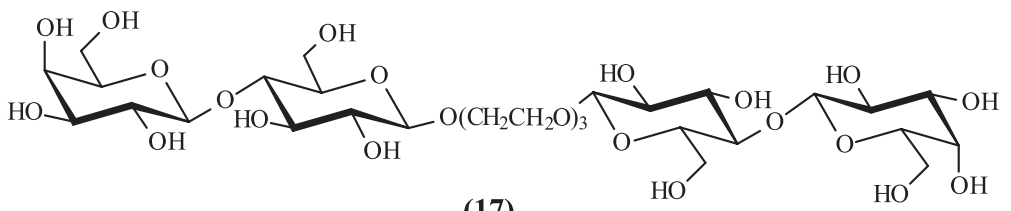

(17)
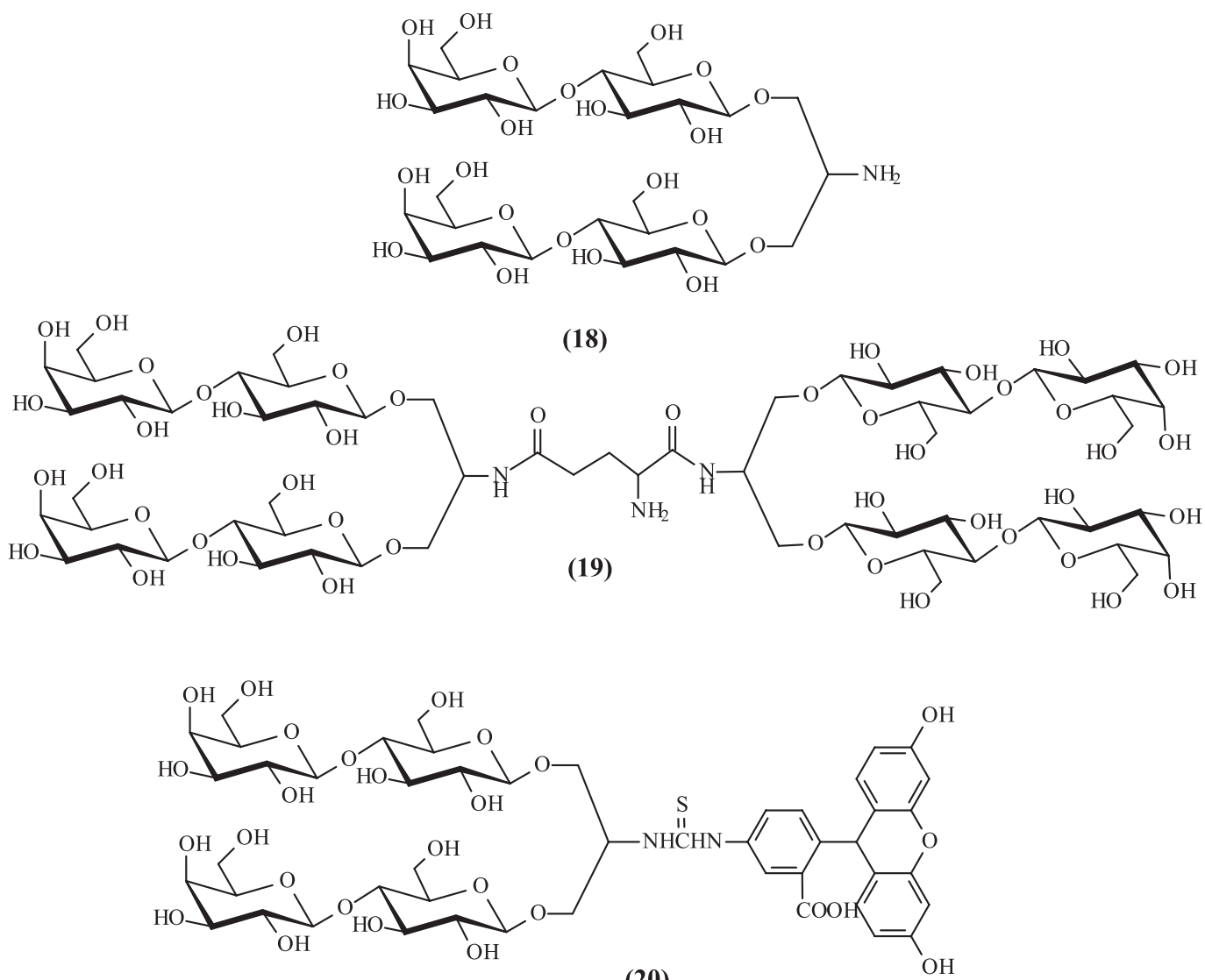

(20)

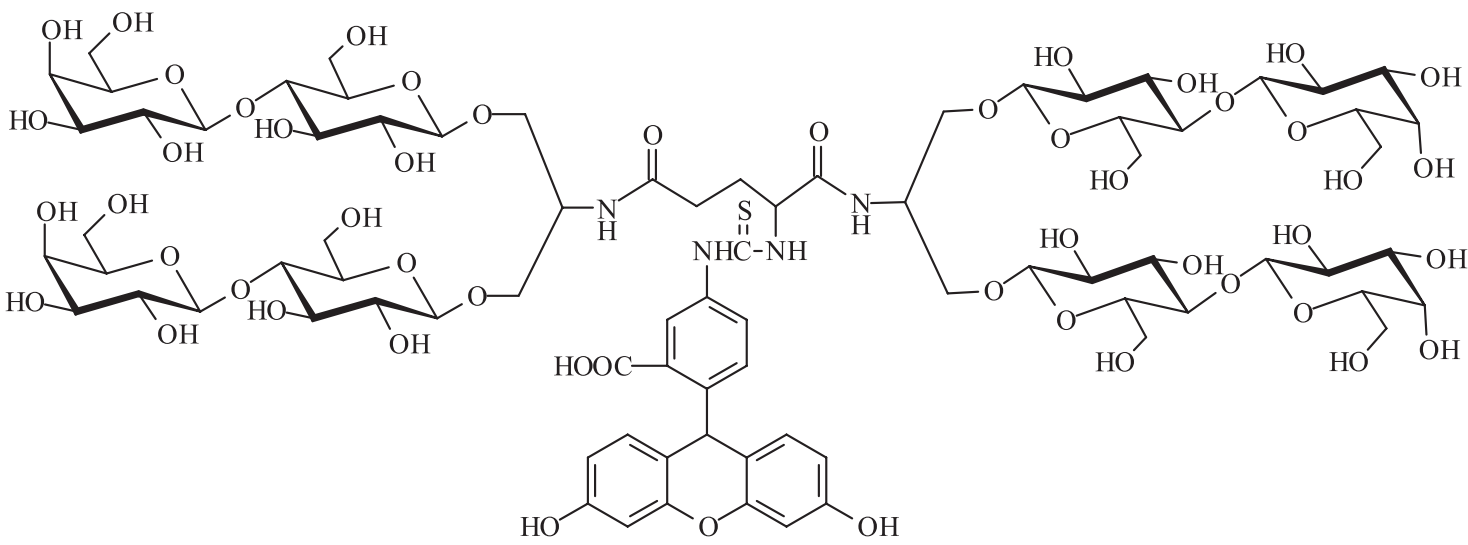

(21)

vary depending on strain and origin. Genome consists of eight single-stranded RNA segment of negative polarity, which significant enhances stability of the virus during replication.

Viruses distributed in embryonated chicken eggs are mostly spherical with a diameter of about $100 \mathrm{~nm}$. There are three proteins on the surface of influenza virus: an M2 ion channel protein, the lectin hemagglutinin (HA) and the sialidase enzyme neuraminidase (NA). ${ }^{[26]}$ HA mediates cell attachment by binding sialic acid (SA) residues on host glycoproteins and glycolipids, thus initiating infection. NA catalyzed the cleavage of SA reduces from glycans on the host surface and is therefore responsible for virus release. The M2 protein plays an important role in uncoating the virus envelope and exposing it content to the cytoplasm of the host cell. ${ }^{[27]}$

The influenza infection is a well-known example of a cell-virus interaction mediated by sialic acids. As opposed to selectin-carbohydrate interactions, where glycan moieties are not necessary required, sialic acid 

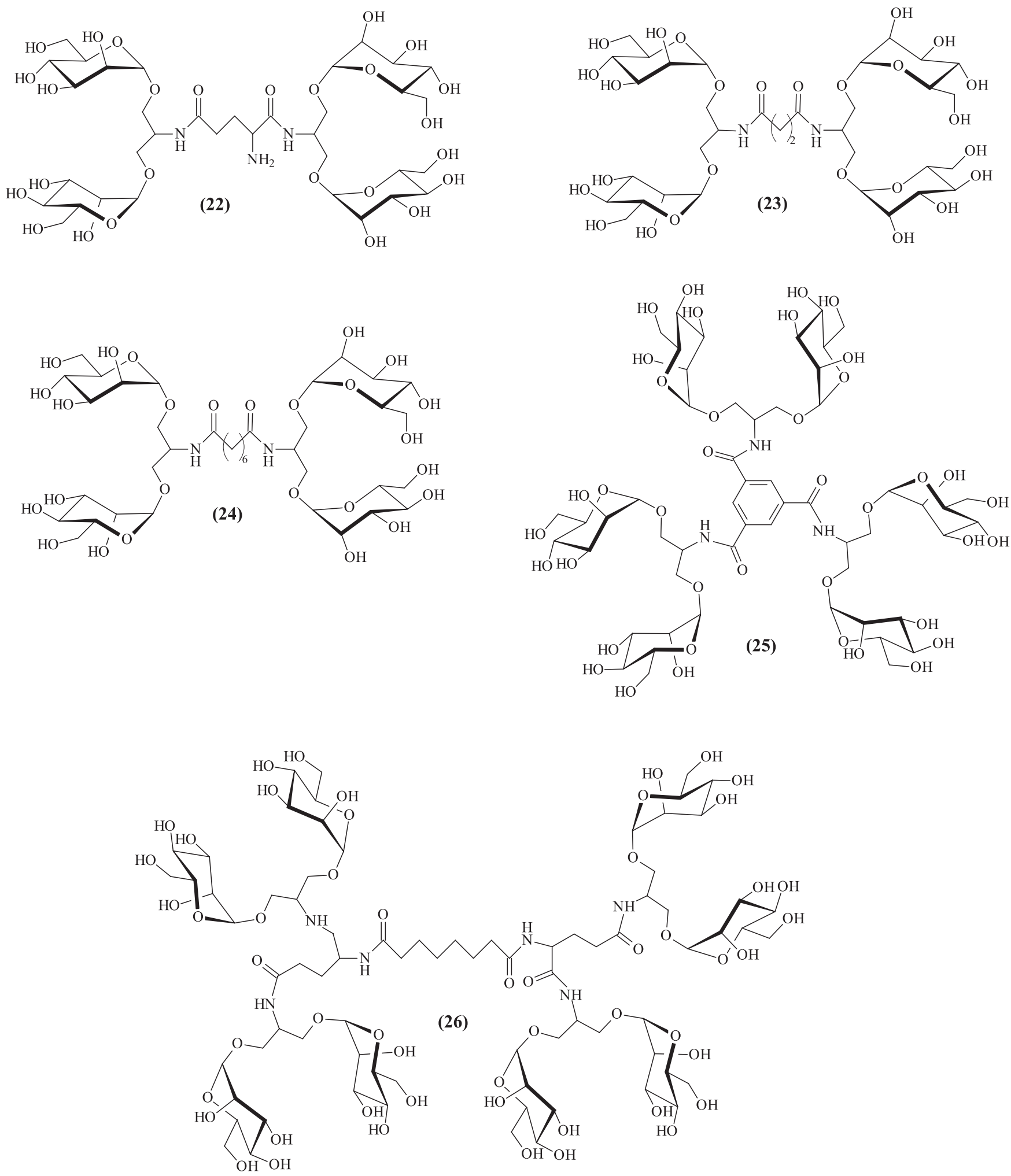

functionalities appeared essential for favorable conditions of adhesion in influenza infections. In general, the influenza virus adheres to the host-cell by using surface glycoprotein HA to recognize glycoconjugates, which present terminal $\alpha$-linked $N$-acetylneuraminic acid ( $\alpha$-Neu5Ac) residues that are widely accepted form of sialic acid found in humans. ${ }^{[28]}$

Another form of sialic acid is $\alpha$-Neu5Gc ( $\alpha$-linked $N$-glycolylneuraminic acid), which bears a hydroxyl group at the $\mathrm{N}$-acyl position and present mostly in animals. In addition to Neu5Ac and Neu5Gc there are at least 50 forms of sialic acid which were founded in nature. ${ }^{[2]}$ The carbohydrate binding specificity of the virus is depend on the species of origin. Human viruses (H3N2) bind to glycans with terminal Neu5Ac 2 structures and galactose residues at the 6-position, whereas, viruses of avian origin (H5N1) preferentially bind to glycans with terminal Neu5Ac $\alpha 2$ structures and 3-position of $D$-galactose. ${ }^{[30]}$ 


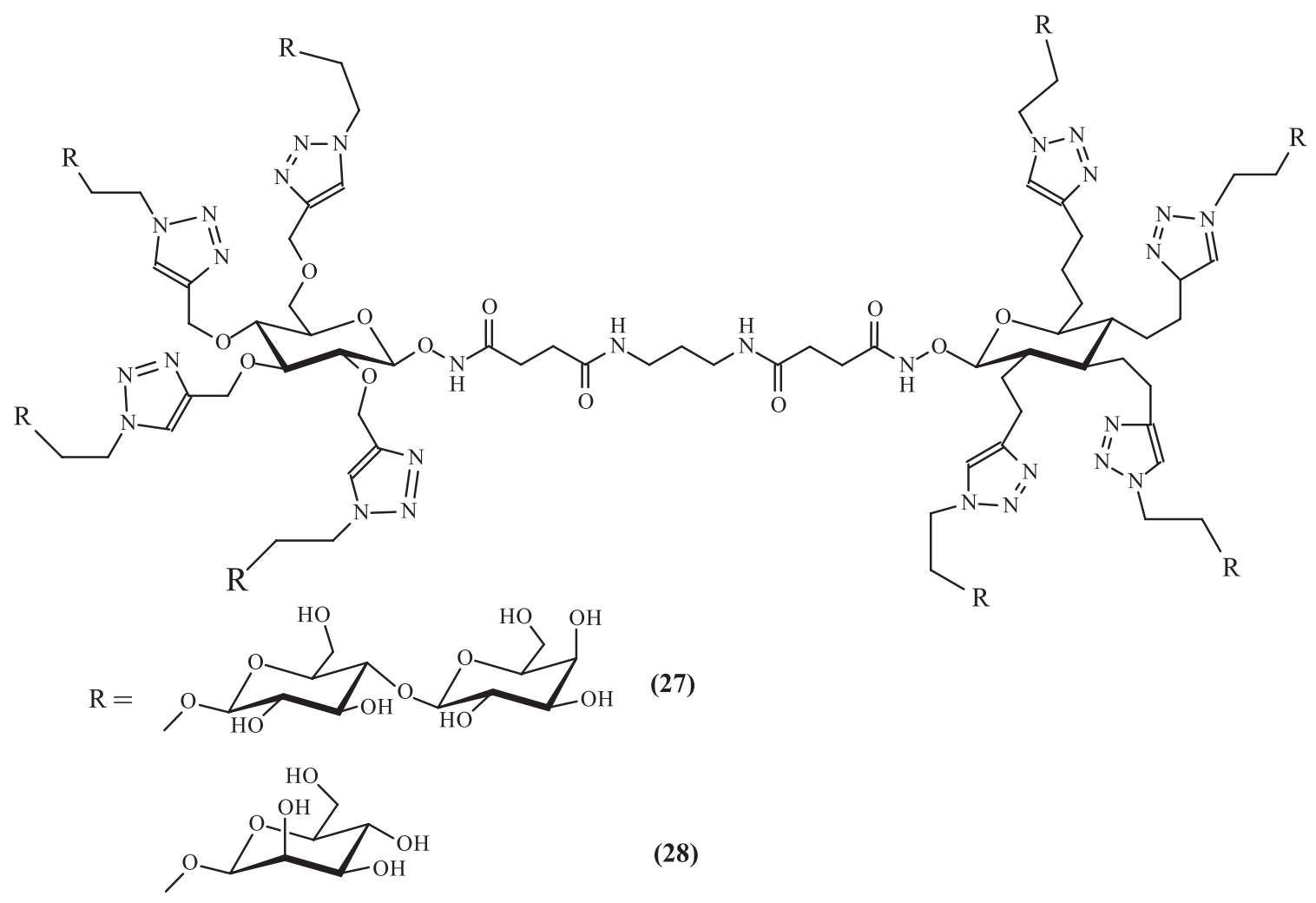

Human immunodeficiency virus (HIV) represents one of the overarching challenges of medical research. Multivalent glycoconjugates can be utilized in novel vaccine approaches or as inhibitors of first step of infection. One of the main pathway of HIV infection is mediated by antigen-presenting cells (APC) at the mucosal endothelium. The terminal $D$-mannose residue of envelope glycoprotein gp120 promote HIV infection by interaction with C-type lectin DC-SIGN (dendritic cell-specific ICAM 3-grabbing non-integrin) expressed on dendritic cells. Dendriric cells, a main group of APC, migrate to the lymph nodes where they efficiently transfer the virus by so-called trans-infection to T-lymphocytes where viral replication occurs. Mimicking the surface of the virus is a strategy for designing carbohydratebased antiviral agents against HIV and Ebola infection.

Glycodendritic compounds have been used as tools to study and to prevent the infection process, in which DCSIGN is involved with the aim to develop new antiviral drugs and immune modulators. ${ }^{[31]}$ The glycoconjugation of glycomimetics to dendritic components have provided multivalent compounds with interesting antiviral activity. IC50 in the low nanomolar range have been obtained in biological assays using Ebola viral particles. Also these compounds have shown very good activity as inhibitors of HIV trans-infection T-cells.

Glycodendritic structures have been prepared recently using a convergent approaches with extensive use of the $\mathrm{Cu}^{\mathrm{I}}$ catalyzed azide-alkyne cycloaddition (CuAAC) reaction also known as «click chemistry» (30), (31). In this approach, first and second generation glycodendrons have been prepared, which were conveniently functionalized for further conjugation on different scaffolds including a fullerene molecule or a virus-like particle protein. ${ }^{[32,33]}$

\section{Vaccines Based on Carbohydrates}

Carbohydrate-based vaccines have been at the forefront of efforts to apply carbohydrate chemistry into fields of clinically research. ${ }^{[34]}$ Many currently utilized vaccines are comprised of glycans including vaccinations against Neisseria meningitides (Menactra), Streptococcus pneumonia (Prevnar), Haemophilius influenza type b (Hib; Hiberix, Comvax) and Salmonella typhi (TYPHIM Vi) ${ }^{[35]}$ However, these constructs are derived from natural sources and utilized nonspecific conjugation methods to carrier proteins. Advances in the field of protein conjugation have also expanded the techniques available to generate carbohydrate vaccines, selectively attached to protein carriers. ${ }^{[36,37]}$

The most successful case to utilize synthetically derived vaccine has been the production of the Cuban Hib vaccine; the first clinically approved, fully synthetic carbohydrate vaccine based on the structure of the capsular polysaccharide antigen from Hib (32). The pentasaccharide conjugated to tetanus toxin (TT) is produced under GMP conditions in scales large enough to be incorporated in the Cuba's current system planned vaccination. A similar approach was taken to generate an antimalarial vaccine by automated synthesis of the plycosylphosphatidylinositol (GPI) from the causative agent of malaria Plasmodium falciparum (33). Recipient mice were protected against many of the damaging symptoms, manifested during parasite infection, including malarial acidosis, pulmonary edema, cerebral syndrome and death. In addition, it has been able to generate a vaccine against the Bacillus anthracis spore tetrasaccharide, which was used to increase antibodies against anthrax for detection and imaging data. ${ }^{[38]}$ 
Glycodendrimers as Potential Therapeutic Agents

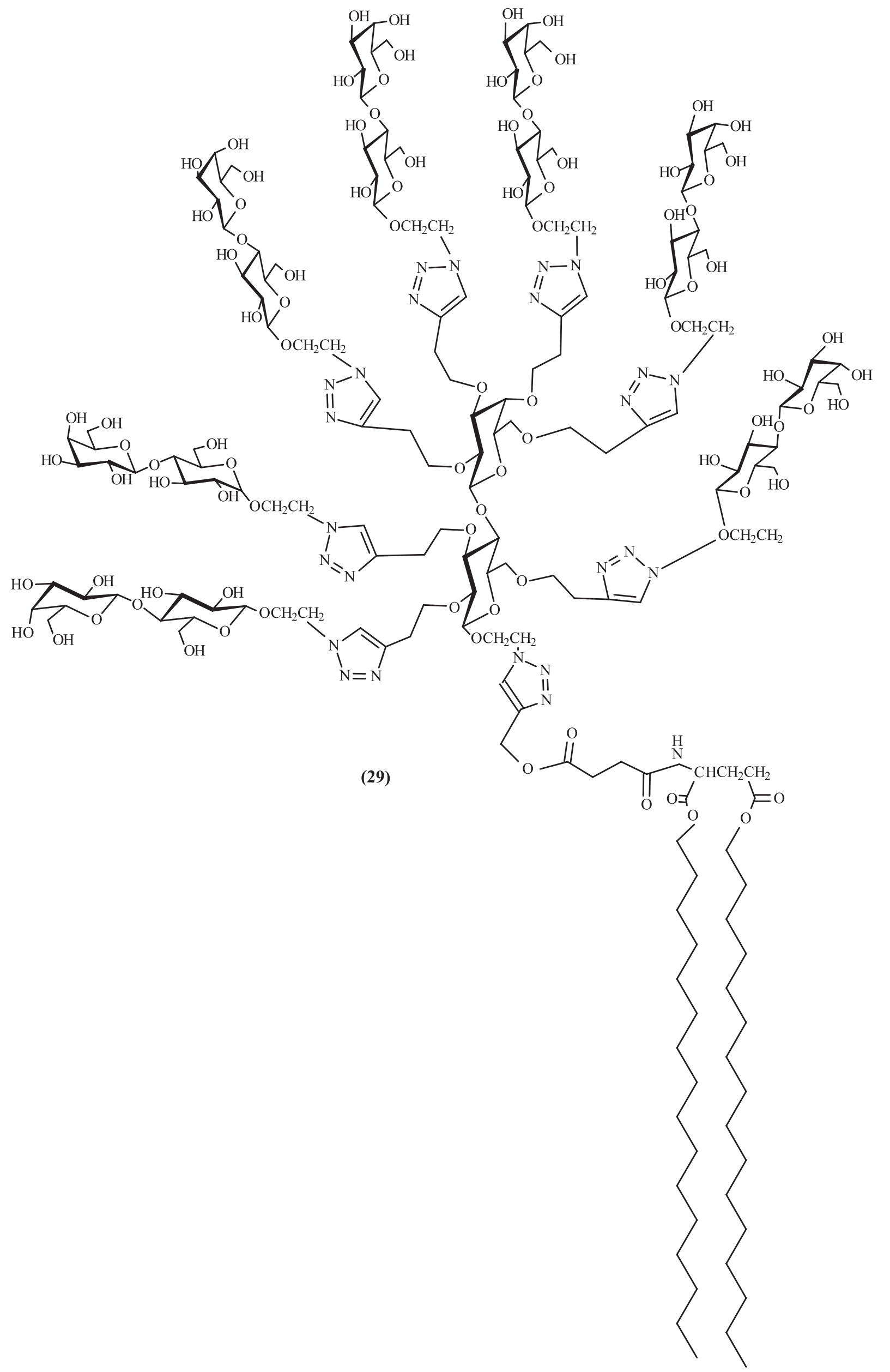




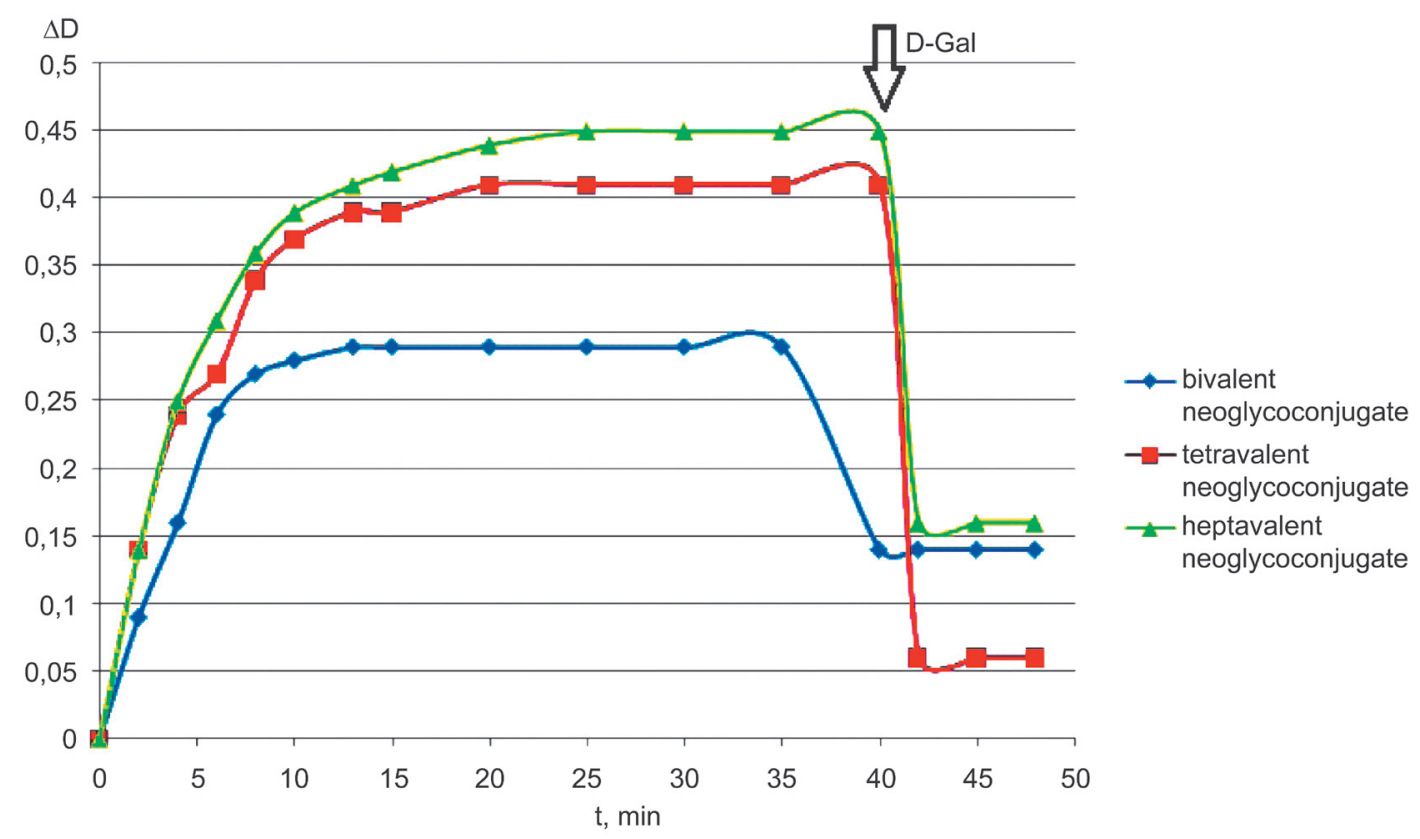

Figure 3. The change dependency of solution optical density on time after binding the modified liposomes by glycoconjugate with lectin $R C A_{1}$.

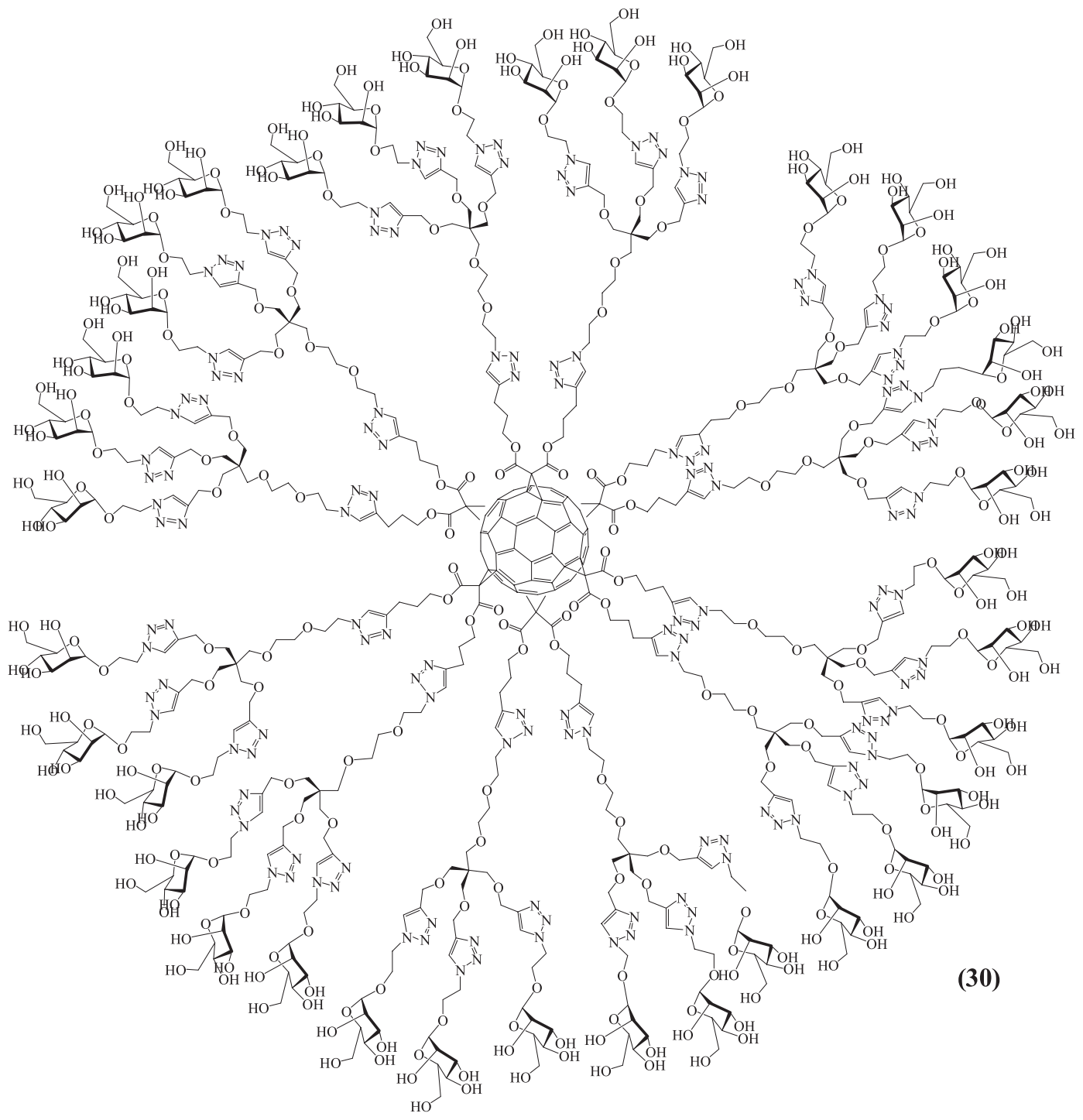




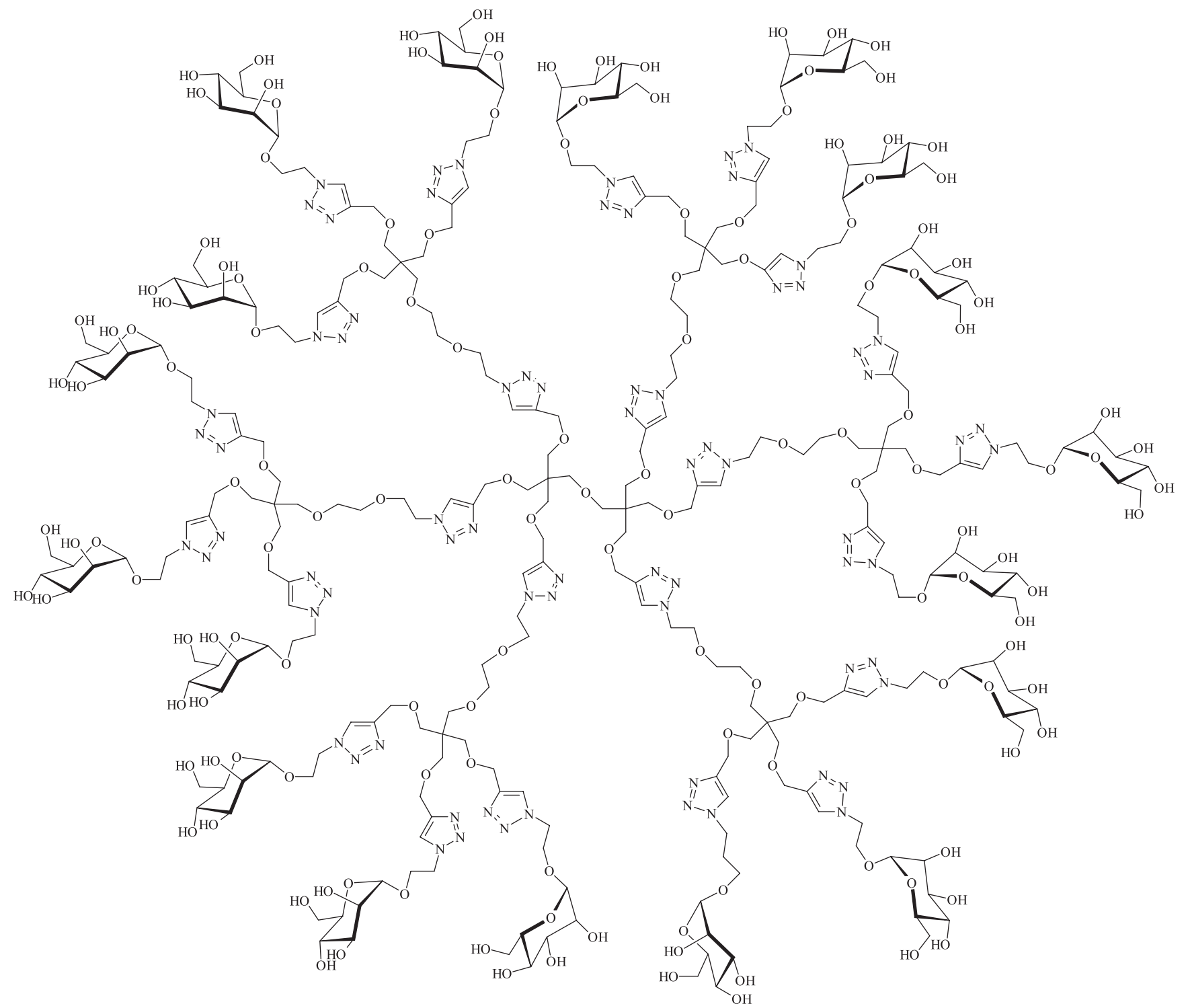

(31)

Synthetic pentadecasaccharide has been described, which consist of three repeating units of the O-specific polysaccharide (O-SP) domain of Shigella flexneri 2a (SF2a) LPS (34). This glycan coupled to tetanus toxoid (TT), induced a better serum anti-LPS $2 \mathrm{f}$ antibody response in mice than shorter synthetic O-SP sequences. The immunized mice successfully produced glycoconjugate-induced anti-LPS antibodies which protected them against SF2a infection. Preclinical data testify that these results are also applicable to human treatment. ${ }^{[39]}$ While the first results were based on archetypal conjugation techniques with monovalent epitopes, new methods are including multivalent epitope structures. A polimer bearing the $\beta$-mannan trisaccharide epitope from the $C$. albicans cell wall conjugated to chicken serum albumin was more resistance to the IgG production in mice, than the trisaccaride-TT conjugate vaccine. ${ }^{[40]}$ In the following research, these antibodies were utilized for identify a minimal disaccharide epitope vaccine that could protect rabbits from fungal burden by live $C$. albicans infection
(35) ${ }^{[41]}$ A series of synthetic oligoglucosamine vaccines, that recognize $\beta$-( $1 \rightarrow 6)$-poly- $N$-acetyl- $D$-glucosamine (PNAG) have been reported, a common constituent in the capsular polysaccharide of many pathogenic bacteria. Antibodies from rabbits, immunized this construct were able to protect mice from $S$. aureus and $E$. coli infections. ${ }^{[42]}$

One of the major discoveries which has sparked interest in the glycobiology field in the past decade was the isolation of neutralizing antibodies for HIV that specific bind with $D$-mannose Man9 glycan of the HIV envelope protein, gp $120 .{ }^{[43,44]}$ The most highly studied vaccine variant is the 2 G12 clone which neutralizes by slowing the entry of the virus into cells and inhibiting replication. ${ }^{[45]}$ Early attempts to elicit an immune response against the high $D$-mannose epitope of gp120 in BSA conjugate were performed in rabbits, but the resulting antibodies were unable to bind the native gp120 $N$-glycans or neutralize the virus.

These results spurred to create a vaccine that used synthetic analogs in place of $D$-mannose to create a more 

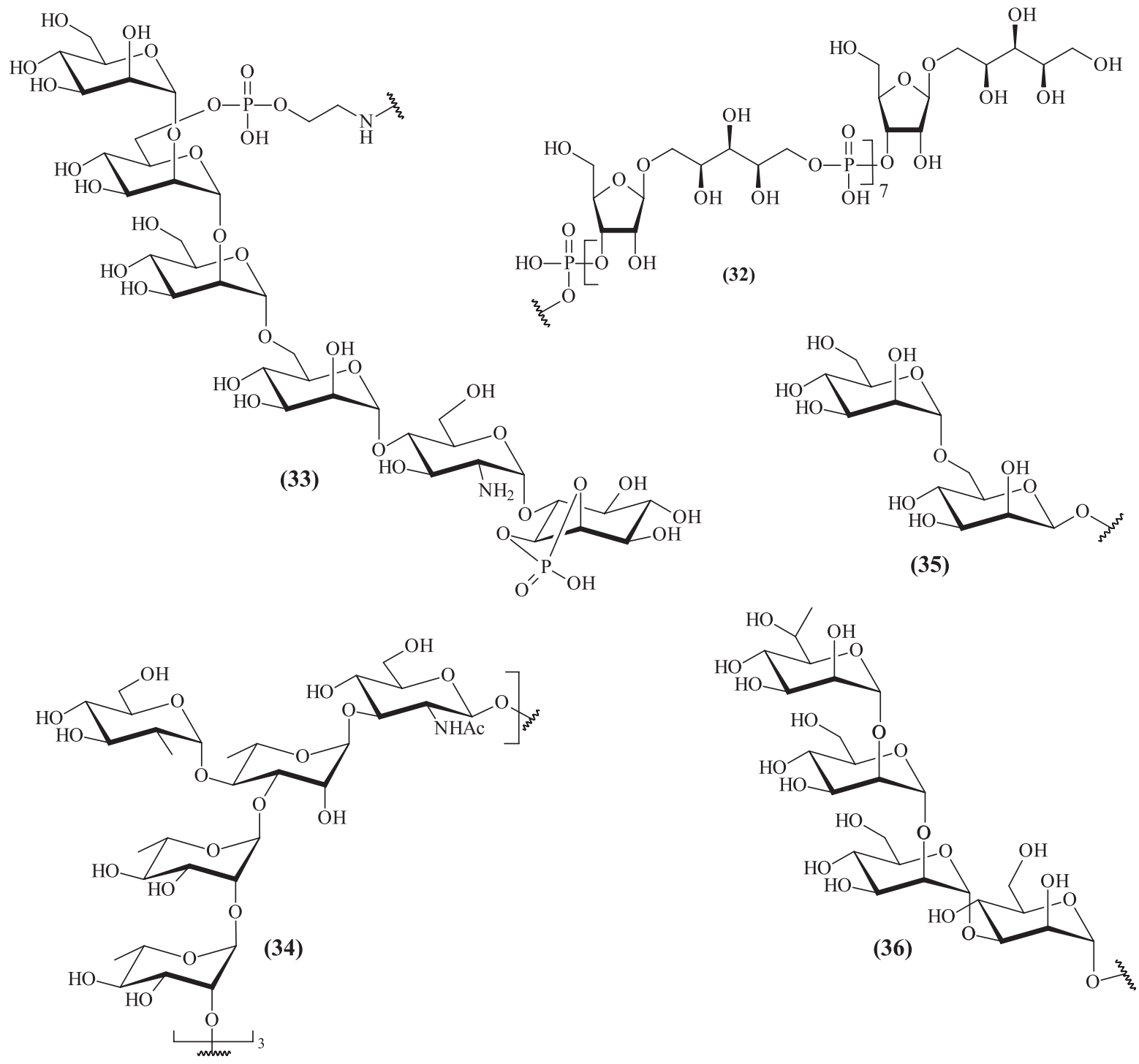

immunogenic epitope (36). Conjugation of this oligomannose mimic with the virus-like particle $\mathrm{Q} \beta$ bound with high affinity to $2 \mathrm{G} 12$ and elicited a greater antibody response than vaccine, including only mannose. Immunization in rabbits produced antibodies that were able to bind well to $\mathrm{Man}_{8}$ and $\mathrm{Man}_{9}$ conjugated to cowpea mosaic virus.

Alterations in the glycosylation of transformed cancer cells have been observed for decades. This change in glycosylation leads to an increase in branched and highly sialylated structures that are often accompanied by an increase in mucinous proteins such as MUC1 and MUC16. Unique repeating glycan epitopes are referred to as TASAs (tumor-associated carbohydrate antigens) have been predominant target for cancer vaccinations. ${ }^{[46]}$ It has been used of synthetically defined carbohydrate vaccines, creating the first synthetic GLOBO $\mathrm{H}$ vaccine for clinical use. Also the vaccine that contains five prostate and breast cancer-associated carbohydrate antigens, Globo-H (37), GM2 (38), STN (39), TF (40), and Tn (41) conjugated to the carrier protein KLH was created. After initial studies demonstrated a successful IgG/IgM response in mice, this construction is currently in clinical trials. ${ }^{[24]}$

\section{Anti-Inflammatory Activity of Glycodendrimers}

It has been reported earlier, the carbohydrates binding with peptides or lectins play very important role in the regulation of the biological processes. ${ }^{[47]}$

The commonly used NSAIDs (Non Steroidal AntiInflammatory Drugs) are eliciting many side effects, such as dyspepsia, gastrointestinal bleeding, perforation in addition to renal trouble. Further high dosages of NSAIDs are leading to acute and chronic conditions. Surfactant encapsulated systems have drawbacks concerning premature and incomplete release of drug owing to their sensitivity to the biological environment. Site-specific targeting of NSAIDs into inflamed regions is important characteristic. It is necessary for suppressing inflammation with minimal side effects and better bioavailability.

Many macromolecular drug delivery systems have been developed to enhance the activity of NSAIDs and limit their side effects, which must be safer than their traditional NSAID derivatives over the years. A macromolecular drug delivery system is a complex structure in which a drug is attached to a carrier molecule such as a synthetic polymer, antibody, hormone or liposome. As the absorption and 

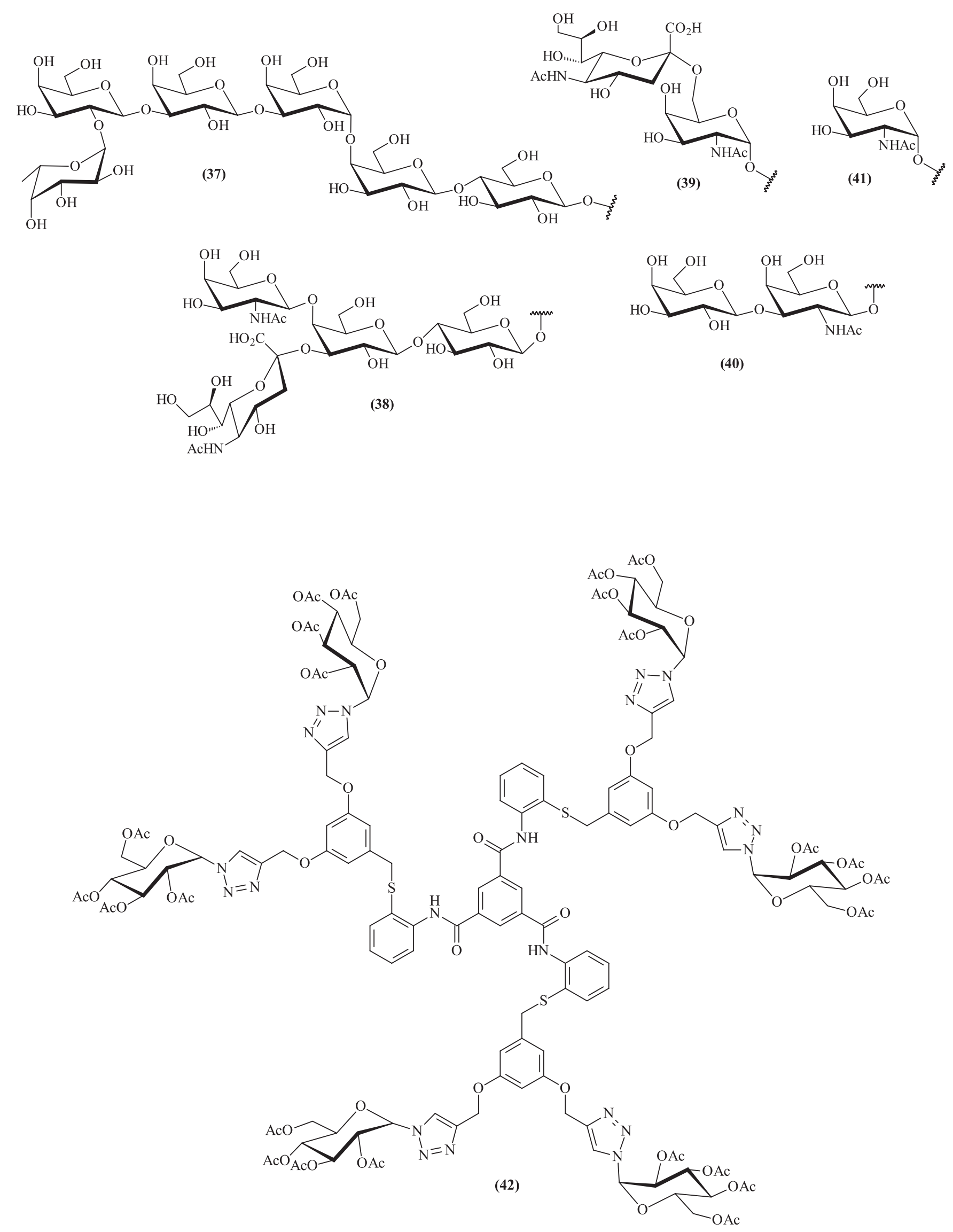


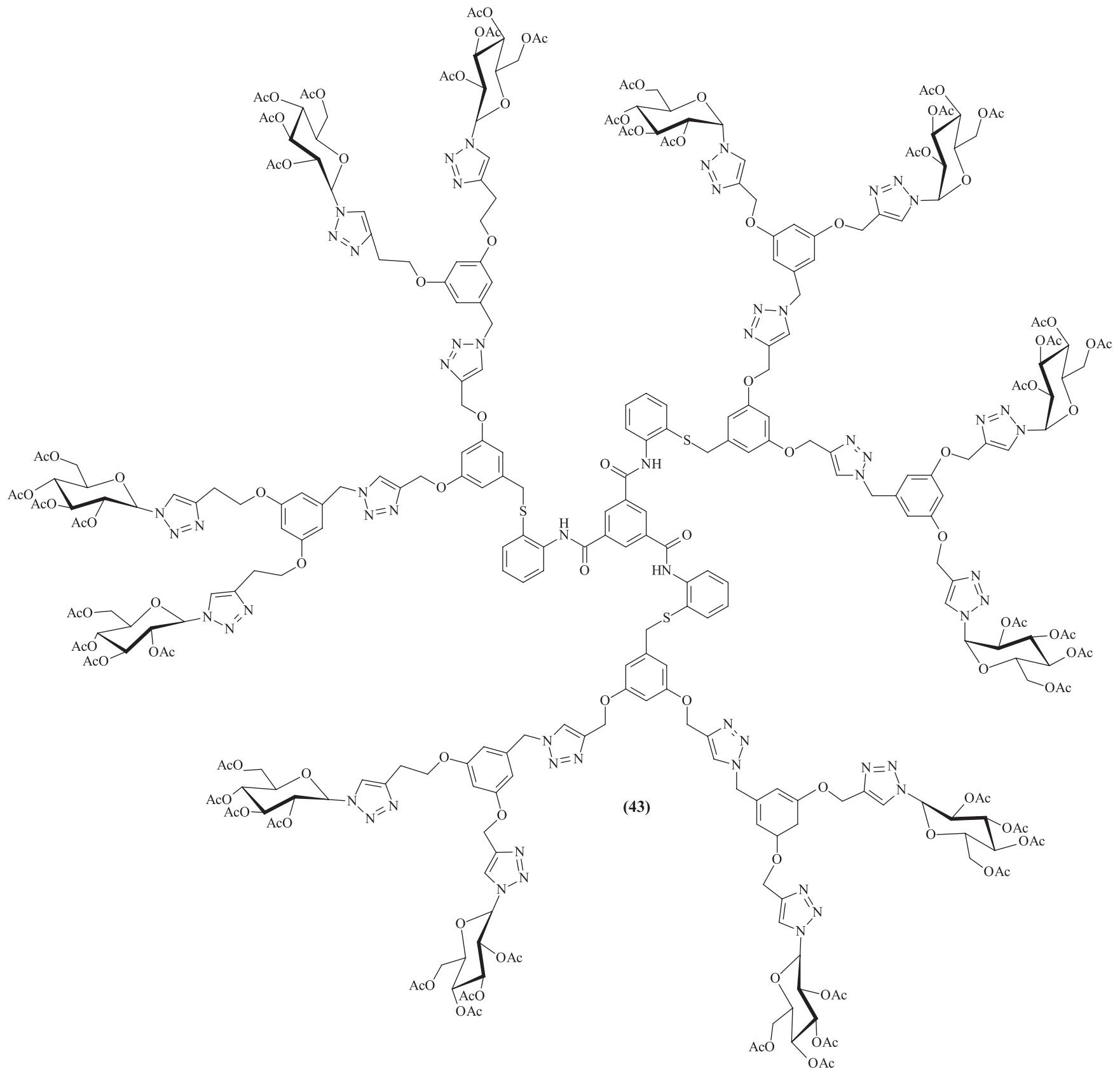

distribution of the drug in such system depend on the properties or parameters of the macromolecular carrier, for example, such as site-binding specificity, modifying the properties of the carrier can protect from degradation and minimization of side effects. Introduction of NSAIDs into delivery systems such as liposome or traditional polymers has been reported to significantly reduce such side effects. PAMAM dendrimers were shown to be effective as nanoscale vectors for the controlled delivery of a variety of NSAID and steroidal type anti-inflammatory drugs. ${ }^{[48]}$

Polyvalent carbohydrate-containing conjugates have complex receptor-binding properties and can be used as immunomodulatory, antiangiogenic and anti-inflammatory agents. ${ }^{[49]}$
In vitro anti-inflammation activity was studied by human red blood cell membrane stabilization method. The lysosomal enzymes evolved during inflammation process. The extracellular activity of these enzymes is related to acute or chronic inflammation. The anti-inflammation agent acts by either inhibiting the lysosomal enzymes or by stabilizing lysosomal membranes. The lysosomal enzymes released during inflammation produced a variety of disorders. Hence lysis of human red blood cell membrane is taken as a measure of anti-inflammatory activity of the drugs.

Anti-inflammatory activity of the glycodendrimers 42-44 could be due to their binding on to the erythrocyte membrane with subsequent alteration of the charges on the surface of the cells. This might have prevented physical interaction with aggregating agents or promote dispersal 


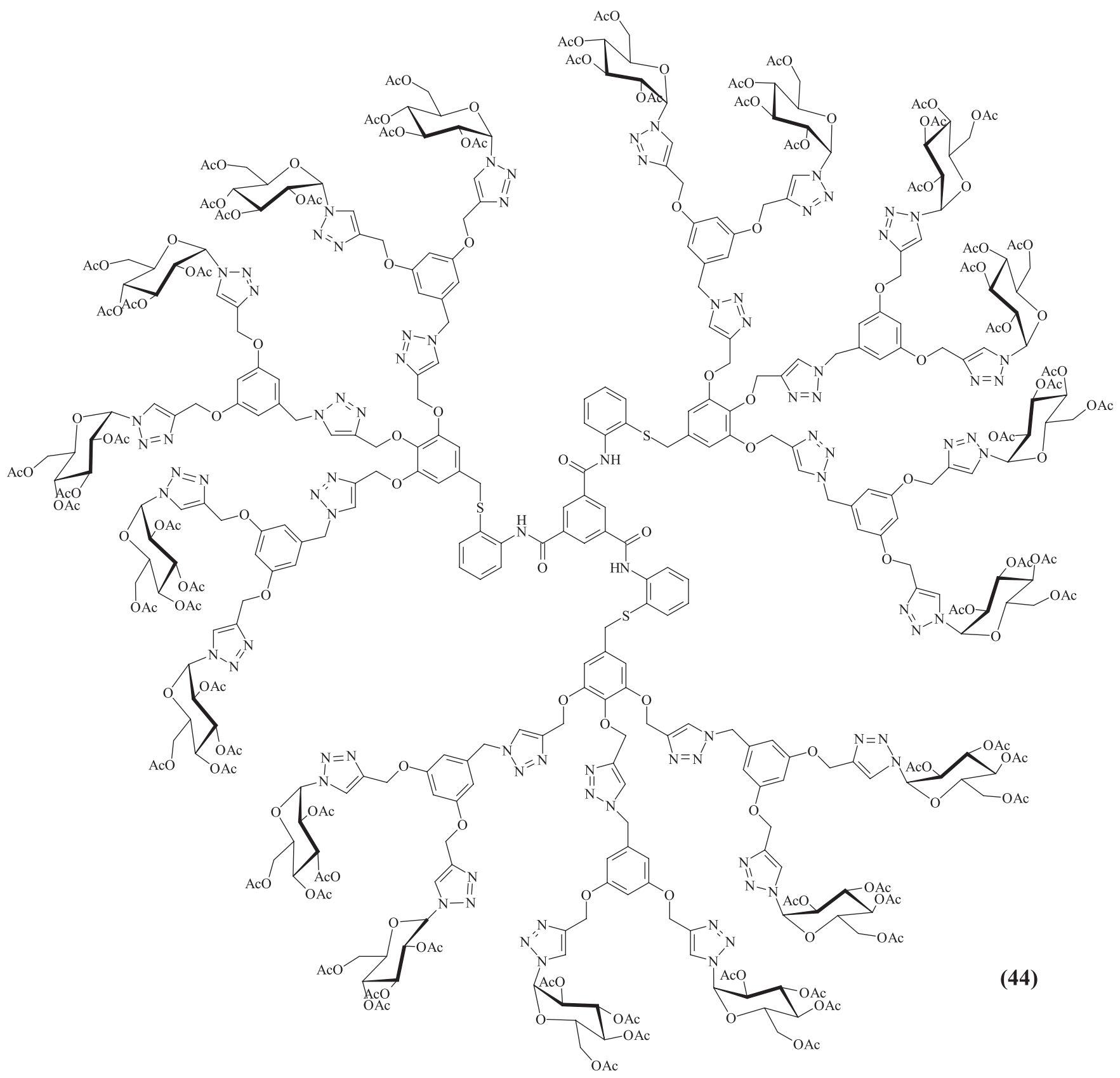

by mutual repulsing of like charges which are involved in the haemolysis of red blood cells. Glycodendrimer 44 shows better anti-inflammatory activity than all other dendrimers at all concentrations which show that its binding on the membrane of the erythrocyte is very effective. This index could be due to the presence of more number of triazol units and multivalent effect of the glycopyranoside surface unit. ${ }^{[50]}$

\section{Conclusion}

Drug development based on the complex carbohydrate and their mimetic are sequentially evolved. It is unmistakable that fundamental investigation of the carbohydrate, one of the most important classes of nature compounds provides the basis of future pharmaceutical market. Carbohydrate chemistry is considerably developed in the field of pharma industry. The most of cell processes leading to, for example, cancer diseases, proceed with the participation of carbohydrate ligands. The excitant of microbial infection also penetrates to the tissue using carbohydrate molecules. Thus, we can safely assume that the carbohydrates will be new perspective agents for diseases treatment in the future.

\section{References}

1. Jason E.H., Carolyn R.B. Chem. Biol. 2014, 21, 16-37.

2. Ju T., Otto V.I. Angew. Chem., Int. Ed. Engl. 2011, 50, 17701791.

3. Muthana S.M., Campbell C.T., Gildersleeve J.C. ACS Chem. Biol. 2012, 7, 31-43.

4. Kooyk van Y., Rabinovich G.A. Nat. Immunol. 2008, 9, 593601. 
5. Ofek I., Hasty D.L., Sharon N. FEMS Immunol. Med. Microbiol. 2003, 38, 181-191.

6. Hartmann M., Lindhorst T.K. Eur. J. Org. Chem. 2011, 35833609.

7. Klein D., Abgottspon T., Wittwer M., Rabbani S., Herold J., Jiang X., Kleeb S., Scharenberg M., Bezencon J., Gubler E., Pang L., Smiesko M., Cutting B., Schwardt O., Ernst B. J. Med. Chem. 2010, 53, 8627-8641.

8. Chemani C., Imberty A., de Bentzmann S., Pierre M., Wimmerova M., Guery B.P., Faure K. Infect. Immun. 2009, 77, 2065-2075.

9. Chabre Y.M., Giguere D., Blanchard B., Rodrigue J., Rocheleau S., Neault M., Rauthu S., Papadopoulos A., Arnold A.A., Imberty A., Roy R. Chem. Eur. J. 2011, 17, 6545-6562.

10. Cecioni S., Lalor R., Blanchard B., Praly J.-P., Imberty A., Matthews S.E., Vidal S. Chem. Eur. J. 2009, 15, 1323213240.

11. Bartels K.M., Funken H., Knapp A., Brocker M., Bott M., Wilhelm S., Jaeger K.E., Rosenau F. J. Bacteriol. 2011, 193, 1107-1113.

12. Consoli G.M.L., Granata G., Cafiso V., Stefani S., Geraci C. Tetrahedron Lett. 2011, 52, 5831-5834.

13. Andreini M., Anderluh M., Audfray A., Bernardi A., Imberty A. Carbohydr. Res. 2010, 345, 1400-1407.

14. Johansson E.M.V., Kadam R.U., Rispoli G., Crusz S.A., Bartels K.M., Diggle S.P., Camara M., Williams P., Jaeger K.E., Darbre T., Reymond J.L. MedChem Comm. 2011, 2, 418-420.

15. Lameignere E., Malinovska L., Slavikova M., Duchaud E., Mitchell E.P., Varrot A., Sedo O., Imbert A., Wimmerova M. Biochem. J. 2008, 411, 307-318.

16. Rieger J., Freichels H., Imberty A., Putaux J.L., Delair T., Jerome C., Auzely-Velty R. Biomacromolecules 2009, 10, 651-657.

17. Clark B.E., Auyeung K., Fregolino E., Parrilli M., Lanzetta R., DeCastro C., Pantophlet R. Chem. Biol. 2012, 19, 254-263.

18. Bai X., Findlow J., Borrow R. Expert Opin. Biol. Ther. 2011, 11, 969-985.

19. D’Errico G., Silipo A., Mangiapia G., Vitiello G., Radulescu A., Molinaro A., Lanzetta R., Paduano L. Phys. Chem. Chem. Phys. 2010, 12, 13574-13585.

20. Durka M., Buffet K., Iehl J., Holler M., Nierengarten J.F., Vincent S.P. Chem. Eur. J. 2012, 18, 641-651.

21. Astronomo R.D., Kaltgrad E., Udit A.K., Wang S.K., Doores K.J., Huang C.Y., Pantophlet R., Paulson J.C., Wong C.H., Finn M.G., Burton D.R. Chem. Biol. 2010, 17, 357-370.

22. Kaila N., Janz K., DeBernardo S., Bedard P.W., Camphausen R.T., Tam S., Tsao D.H.H., Keith Jr. J.C., Nickerson-Nutter C., Shilling A., Young-Sciame R., Wang Q. J. Med. Chem. 2007, 50, 21-39.

23. Castro G.R., Panilaitis B., Bora E., Kaplan D.L. Mol. Pharm. 2007, 4, 33-46.

24. Qing Li, Ting-Ting Yan, Shan Niu, Yue-Tao Zhao, Xiang-Bao Meng, Zhi-Hui Zhao, Zhong-Jun Li Carbohydr. Res. 2013, 379, 78-94.
25. Kurochkina N.A., Budanova U.A., Sebyakin Yu.L. Russ. J. Org. Chem. 2014, 50, 1496-1503.

26. Al-Majhdi F.N. J. Biol. Sci. 2007, 7, 113-122.

27. Whittaker G.R. Exp. Rev. Mol. Med. 2001, 3, 1-13.

28. Webster R.G., Bean W.J., Gorman O.T., Chambers T.M., Kawaoka Y. Microbiol. Mol. Biol. Rev. 1992, 56, 152-179.

29. Angata T., Varki A. Chem. Rev. 2002, 102, 439-470.

30. Ilona P. Multivalent Glycoarchitectures of Different Dimentions and their Biological Evaluation. Doc. diss. 2011, Free University of Berlin.

31. Sánchez-Navarro M., Rojo J. Drug News Perspect. 2010, 23, 557-572.

32. Astronomo R.D., Kaltgrad E., Udit A.K., Wang S.K., Doores K.J., Huang C.Y., Pantophlet R., Paulson J.C., Wong C.H., Finn M.G., Burton D.R. Chem. Biol. 2010, 17, 357-370.

33. Astronomo R.D., Lee H.K., Scanlan C.N., Pantophlet R., Huang C.Y., Wilson I.A., Blixt O., Dwek R.A., Wong C.H., Burton D. J. Virol. 2008, 82, 6359-6368.

34. Boltje T.J., Buskas T., Boons G.-J. Nat. Chem. 2009, 1, 611622.

35. Morelli L., Poletti L., Lay L. Eur. J. Org. Chem. 2011, 57235777.

36. Gamblin D.P., Scanlan E.M., Davis B.G. Chem. Rev. 2009, 109, 131-163.

37. Grayson E.J., Bernardes G.J.L., Chalker J.M., Boutureira O., Koeppe J.R., Davis B.G. Angew. Chem., Int. Ed. 2011, 50, $4127-4132$.

38. Tamborrini M., Werz D.B., Frey J., Pluschke G., Seeberger P.H. Angew. Chem., Int. Ed. 2006, 45, 6581-6582.

39. Phalipon A., Tanguy M., Grandjean C., Guerreiro C., Cohen D., Sansonetti P.J., Mulard L.A. J. Immunol. 2009, 182, 2241-2247.

40. Lipinski T., Kitov P.I., Szpacenko A., Paszkiewicz E., Bundle D.R. Bioconjug. Chem. 2011, 22, 274-281.

41. Bundle D.R., Nycholat C., Costello C., Rennie R., Lipinski T. ACS Chem. Biol. 2012, 7, 1754-1763.

42. Gening M.L., Maira-Litran T., Kropec A., Skurnik D., Grout M., Tsvetkov Y.E., Nifantiev N.E., Pier G.B. Infect. Immun. 2010, 78, 764-772.

43. McCoy L.E., Weiss R.A. J. Exp. Med. 2013, 210, 209-223.

44. Pejchal R., Doores K.J., Walker L.M., Khayat R., Huang P.S., Wang S.K., Stanfield R.L., Julien J.P., Ramos A., Crispin M. Science 2011, 334, 1097-1103.

45. Platt E.J., Gomes M.M., Kabat D. Proc. Natl. Acad. Sci. USA 2012, 109, 7829-7834.

46. Pashov A., Monzavi-Karbassi B., Kieber-Emmons T. Hum. Vaccin. 2011, 7, 156-165.

47. Bolsheborodova A.K., Sebyakin Yu.L. Macroheterocycles 2012, 5, 203-211.

48. Rajakumar P., Abdul Rasheed A.M., Rabia A.I., Chamundeeswari D. Bioorg. Med. Chem. Lett. 2006, 16, 6018-6019.

49. Chauhan A.S., Diwan P.V., Jain N.K., Tomalia D.A. Biomacromolecules 2009, 10, 1194-1195.

50. Rajakumar P., Anandhan R. Eur. J. Med. Chem. 2011, 46, 4687-4695. 